\title{
APASL clinical practice guidance: the diagnosis and management of patients with primary biliary cholangitis
}

\author{
Hong You ${ }^{1} \cdot$ Xiong $\mathrm{Ma}^{2} \cdot$ Cumali Efe $^{3} \cdot$ Guiqiang Wang $^{4} \cdot$ Sook-Hyang Jeong ${ }^{5} \cdot$ Kazumichi Abe $^{6} \cdot$ Weijia Duan $^{1}$. \\ Sha Chen ${ }^{1}$. Yuanyuan Kong ${ }^{7}$. Dong Zhang ${ }^{8}$. Lai Wei ${ }^{9} \cdot$ Fu-Sheng Wang ${ }^{10} \cdot$ Han-Chieh Lin $^{11} \cdot$ Jin Mo Yang $^{12}$. \\ Tawesak Tanwandee ${ }^{13} \cdot$ Rino A. Gani ${ }^{14}$. Diana A. Payawal ${ }^{15}$. Barjesh C. Sharma ${ }^{16}$. Jinlin Hou ${ }^{17}$. Osamu Yokosuka ${ }^{18}$. \\ A. Kadir Dokmeci ${ }^{19}$. Darrell Crawford ${ }^{20}$. Jia-Horng Kao ${ }^{21} \cdot$ Teerha Piratvisuth $^{22}$. Dong Jin Suh ${ }^{23}$. \\ Laurentius A. Lesmana ${ }^{24}$. Jose Sollano ${ }^{25}$. George Lau ${ }^{26}$. Shiv K. Sarin ${ }^{27} \cdot$ Masao Omata $^{28,30}$. Atsushi Tanaka ${ }^{29}$. \\ Jidong Jia ${ }^{1}$ (D)
}

Received: 6 April 2021 / Accepted: 8 November 2021 / Published online: 4 February 2022

(c) The Author(s) 2022

\section{Introduction}

Primary biliary cholangitis (PBC) is a chronic intrahepatic cholestatic disease with not fully elucidated pathogenesis. Immunological dysfunction triggered by environmental factors may render autoimmunity against the interlobular bile ducts in genetically predisposed hosts. PBC typically affects middle-aged women, commonly presents with fatigue and pruritus, or with an asymptomatic elevation of serum alkaline phosphatase (ALP)/glutamyl transpeptidase (GGT). The pathological features are progressive, non-suppurative, destructive intrahepatic cholangitis, leading to fibrosis and eventually cirrhosis. Antimitochondrial antibodies (AMAs), especially the M2 subtype (AMA-M2), are highly sensitive and specific for PBC in clinical settings. Currently, ursodeoxycholic acid (UDCA) is the treatment of choice for this disease.

In response to the increasing report of this once-regarded rare disease of the Western world in the Asia-Pacific region, a panel of invited expert hepatologists and methodologists developed the Asian Pacific Association for the Study of the Liver (APASL) Clinical Practice Guidance on the Diagnosis and Management of Patients with Primary Biliary Cholangitis.

\section{Guidance development process}

The invited panel of clinicians with expertise in PBC and methodologists with special interest in clinical research of liver diseases drafted and discussed this guidance. We

Hong You, Xiong Ma and Cumali Efe should be considered cofirst authors.

Extended author information available on the last page of the article conducted a formal literature review of evidence from PubMed and Cochrane database as of January 2021. In developing recommendations and supporting texts, the expert methodologists assisted in assessing the quality of identified evidence using the Grading of Recommendations Assessment Development and Evaluation (GRADE system) [1] (Table 1).

\section{Epidemiology}

PBC may affect all races and ethnicities with great geographical variation $[2,3]$. Overall, the estimated global incidence and prevalence were 17.6 per million persons/year and 146 per million, respectively [3]. The reported incidence and prevalence of $\mathrm{PBC}$ in the Asia-Pacific region (8.4, and 98.2-118.8 per million, respectively) were lower than that in North America (27.5 and 218.1 per million, respectively) and Europe (18.6 and 145.9 per million, respectively) [3, 4]. Of note, the geographical differences in PBC epidemiology exist even within the Asia-Pacific region,with a higher reported prevalence in Japan and China (191.18 per million) and a much lower reported prevalence in South Korea and Australia (39.09 per million) [4]. Interestingly, the reported prevalence of PBC in New Zealand and Australia is much lower than that in Europe despite the fact that their populations share similar genetic background, adding further weight to the hypothesis that environmental factors may play a role in the etiopathogeneis of $\mathrm{PBC}[5,6]$.

The prevalence of $\mathrm{PBC}$ in the Asia-Pacific region has become higher than once deemed and increased quickly [3, 7-14]. A recent study in Japan demonstrated that the point prevalence of $\mathrm{PBC}$ was 338 per million, which was comparable to that in Europe and North America [12]. Another 
Japanese study reported that PBC was diagnosed in 5.7\% of the women with asymptomatic serum GGT elevation (6.0\% among all the women) at the annual health check-up among a large population, yielding an estimated PBC prevalence of 3400 per million in women over 40 years old and 840 per million in the whole population in Okinawa Prefecture [7].

\section{Pathogenesis}

The interplay of environmental, genetic/epigenetic, and immunological factors play a crucial role $[15,16]$, although the exact pathogenesis of PBC remains elusive. Environmental factors, such as cigarette smoking [17], toxin exposure [18], and infectious agents [19], may breakdown the immune tolerance in individuals with genetic susceptibility. It has been reported that infected microbes could act as cross-antigens and cause molecular mimicry, thereby breaching the self-tolerance and initiating autoimmune reactions against intrahepatic bile ducts [15]. Meanwhile, gut dysbiosis and geographical clustering of $\mathrm{PBC}$ cases indicate that gut microbiota and environmental influence may be potential risk factors for the disease [20,21].

Familial and genetic studies highlight the importance of genetic susceptibility for PBC. Recently, genome-wide association studies (GWAS) have identified multiple genes conferring PBC susceptibility in human leucocyte antigen (HLA) and non-HLA loci [22, 23]. Studies have shown that HLA DRB $1 * 11$ and HLA-DRB $1 * 13$ are protective against PBC in European cohorts, whereas HLA-DQB 1*06:04 and $\mathrm{DQB} 1 * 03: 01$ are protective against the disease in Japanese cohorts [16]. In Chinese Han, HLA-DQB 1*03:01 confers PBC resistance, whereas HLA-DRB $1 * 08: 03$ and HLADPB $1 * 17: 01$ confer PBC susceptibility [16]. Moreover, it is reported that HLA-DRB1*03:01 was significantly associated with anti-sp100 positive subphenotype of $\mathrm{PBC}$ in Chinese Han [24].

One of the significant non-HLA genes revealed by the GWAS is the interleukin-12 (IL-12) pathway, which may participate in developing auto-reactive Th1 cells, thereby rendering the PBC onset [22, 25]. Recently, a Japanese study on meta-analysis of GWAS and bioinformatics demonstrated that protein O-glucosyltransferase 1 (POGLUT1) is the effector gene regulated by the primary functional SNP rs2293370 (a susceptibility locus for PBC on chromosome 3q13.33) [26]. In turn, higher endogenous levels of POGLUT1 may induce excessive Notch signaling, thereby mounting immune responses against self-antigens [26]. Genetic studies in Chinese Han population have not only confirmed associations of several risk loci previously found in Europeans or Japanese, but also identified novel risk factors for PBC, such as desregulation of IL-21 signaling pathway [27]. Notably, known risk variants merely account for less than $20 \%$ heritability of PBC, indicating that other factors contribute to their genetic background.

The innate immunity is implicated in the pathogenesis of $\mathrm{PBC}$, as indicated by the presence of granulomatous inflammation, the hypersecretion of proinflammatory cytokines and polyclonal immunoglobulin $\mathrm{M}(\operatorname{IgM})$, the elevation of NK and NKT cells, as well as noticeable hyperresponsiveness to $\mathrm{CpG}$ oligodeoxynucleotides [28, 29]. Pathogen-associated molecular patterns (PAMP) can bind to toll-like receptors (TLRs) on the surface of biliary epithelial cells (BECs) and innate immune cells, thereby triggering innate immunity [30]. Meanwhile, monocytes, activated by the PAMP through TLRs, participate in the modulation or amplification of adaptive cellular immune response by secreting proinflammatory cytokines (e.g., IL-1, IL-6, IL-12, and TNF- $\alpha$ ) [31]. During PBC progression, abnormaly retented bile acids can signal through various nuclear receptors, thereby regulating immune responses [32].

The adaptive immunity also participates in the pathogenesis of $\mathrm{PBC}$, as indicated by the presence of a high concentration of antimitochondrial antibodies specific for 2-oxoacid dehydrogenase complex (2-OADC) and the increase of antigen-specific CD4+ and CD8+ T cells [25]. CD8+ T cells are the predominant infiltrating lymphocytes in the liver tissues of PBC patients, which express FasL and secret perforin thereby leading to apoptosis of BECs [33]. Regulatory $\mathrm{T}$ lymphocytes (Treg), which suppress self-reactive CD8+lymphocytes and regulate inappropriate immune responses, are significantly lower in $\mathrm{PBC}$ patients and their family members [34]. This finding suggests that dysfunction of the Treg cells may reduce immune tolerance and confer effector lymphocytes to damage the BEC. Besides, myeloidderived suppressor cells [35], double-negative T cells (DNT) [36], and mucosal-associated invariant T cell (MAIT) [37] were also implicated in the development of PBC. However, the exact roles of these cells are still not fully elucidated.

Intriguingly, injured BECs of $\mathrm{PBC}$ patients can express higher level of HLA class II molecules and act as non-professional antigen-presenting cells. The interplay of BECs and $\mathrm{T}$ cells may, to some extent, account for bile duct loss, a key characteristic of disease progression [25]. Additonally, the bone marrow (BM) microenvironment might also play a role in the pathogenesis of $\mathrm{PBC}$. The hemopoietic progenitor cells and stromal cells were defective [38], and the BM cytokines and apoptotic process were altered in PBC [39, 40].

Putting together, the interplay of environmental and immunological factors in an individual with genetic susceptibility breaches the autotolerance to and mounts autoimmunity against the intrahepatic BECs, thereby leading to the characteristic pathological and clinical phenotypes of PBC (Fig. 1). 
Table 1 Grading evidence and recommendations

\begin{tabular}{|c|c|}
\hline \multicolumn{2}{|c|}{ Grade of evidence } \\
\hline I & High quality: Further research is very unlikely to change our confidence in the estimate of effect \\
\hline II & $\begin{array}{l}\text { Moderate quality: Further research is likely to have an important impact on our confidence in the estimate of effect } \\
\text { and may change the estimate }\end{array}$ \\
\hline III & $\begin{array}{l}\text { Low quality: Further research is very likely to have an important impact on our confidence in the estimate of effect } \\
\text { and is likely to change the estimate }\end{array}$ \\
\hline IV & Very low quality: Any estimate of effect is very uncertain \\
\hline \multicolumn{2}{|c|}{ Grade of recommendation } \\
\hline 1 & $\begin{array}{l}\text { Strong recommendation: recommendation is made on the consideration of benefit, patients' wishes, cost and } \\
\text { resources }\end{array}$ \\
\hline 2 & Weak recommendation: recommendation is made with less certainty, higher cost or resource consumption \\
\hline
\end{tabular}

\section{Diagnosis of PBC}

\section{Clinical features}

PBC typically affects middle-aged women, with a female to male ratio as high as 10:1 [41-44]. However, the female to male ratio (3.9-6.2:1) was much lower in recently reported cohorts from Korea [11], Japan [12], China Mainland [45], Hong Kong [13] and Taiwan [46].

The clinical manifestation of PBC includes pruritus, fatigue, and, less commonly, jaundice or complications of cirrhosis. Nowadays, an increasing number of asymptomatic patients are diagnosed at an early disease stage mainly due to routine testing of liver biochemistry [47], especially in East Asia. It is reported that the mortality of the elderly asymptomatic PBC patients ( $\geq 55$ years) were similar to that of the age- and sex-matched general population [48]. However, if left undiagnosed or untreated, two thirds of the asymptomatic patients will eventually develop into the symptomatic phase within five years [49].

\section{Common symptoms}

Symptomatic PBC patients usually present with fatigue, pruritus, or jaundice. Fatigue occurs in up to $80 \%$ of patients and fluctuates independently of disease activity or stage [50]. The pathogenesis of fatigue is not entirely clear but central nervous system abnormalities caused by cholestasis and peripheral muscle dysfunction have been implicated, which lead to autonomic dysfunction, daytime sleepiness, night sleep disturbance, impaired concentration, memory problems and depression [51]. The Fatigue Impact Scale (FIS) [52], especially the PBC-40 [53] helps to measure the severity of fatigue in $\mathrm{PBC}$ patients [51]. Early presentation of fatigue severely affects the health-related quality of life (HRQoL) and has been viewed as a predictor of mortality.
Furthermore, fatigue may not be completely resolved by UDCA or even liver transplantation [54].

Pruritus affects $20-70 \%$ of patients, making it another frequent complaint in $\mathrm{PBC}$ patients [55]. A recent crosssectional study in Japan showed that about $30 \%$ of patients with PBC suffered from moderate-to-severe pruritus [56], which is annoying very much but may not be noticed as a manifestation of PBC. Pruritus in PBC is thought to be mediated by pruritogens, such as bile salts, autotaxin, and lysophosphatidic acid, which are normally excreted into the bile but accumulates in the serum as a result of cholestasis [57]. It may occur in any stage, before, at, or after the development of jaundice. Pruritus is usually mild and tolerable in most PBC patients, but it may be severe and persistent in some patients, thus compromise the HRQoL. However, the severity of pruritus seems to not correlate with the disease stage or activity.

\section{Associated diseases and syndromes}

Several extrahepatic autoimmune diseases could coexist with PBC, such as Sjögren's syndrome (3.5-73\%), autoimmune thyroid disease (5.6-23.6\%), systemic sclerosis (1.4-12.3\%), Raynaud's phenomenon (1.8-5.6\%), systemic lupus erythematosus (0-3.7\%), and celiac disease (0-6\%) [58]. Other less recognized diseases with a relatively lower prevalence could also occur in PBC patients. However, these associated syndromes do not change the natural history, clinical presentation, or survival of PBC [59, 60].

Studies found that specific autoantibodies of rheumatologic disorders including antibodies against SS-A/Ro-52kD and centromere might be associated with the diagnosis and poorer prognosis of PBC [61, 62]. Obviously, the significance of these autoantibodies needs to be further explored. 


\section{Complications}

If left untreated, PBC patients with persistent cholestasis will eventually progress to the advanced stage with complications associated with cholestasis and/or cirrhosis.

Hyperlipidemia, which results from complex processes of biliary cholestasis, is common in PBC patients. It can cause xanthelasmas and xanthomas due to the remarkable elevation of high-density lipoprotein cholesterol. Interestingly, this kind of hyperlipidemia seems not to confer an increased risk of cardiovascular disease [63].

Compared with age-matched healthy people, PBC patients are more inclined to have hepatic osteodystrophy, such as osteoporosis which affects around $20-44 \%$ of the patients [64]. Fat-soluble vitamin malabsorption may occur due to decreasing secretion in bile acid, but a significant lack of vitamin A, D, E, and $\mathrm{K}$ are uncommon [65].

Complications associated with cirrhosis and portal hypertension such as ascites, gastroesophageal variceal bleeding, hepatic encephalopathy seem to resemble those caused by other chronic liver diseases. Of note is that signs of portal hypertension can develop even before the establishment of cirrhosis, which is presinusoidal in nature [66]. The risk of hepatocellular carcinoma (HCC) in PBC patients also increased, especially in men or those who have already developed cirrhosis [67-69].

\section{Laboratory tests}

\section{Biochemical tests}

PBC patients may have abnormal biochemical tests, such as increased ALP and GGT, mild elevation of aminotransferases, and elevation of immunoglobulins (mainly IgM). Figure 2 depicts a diagnostic workup for patients with elevated cholestatic enzymes.

\section{Immunological tests}

Anti-mitochondrial antibody (AMA) AMA, particularly the AMA-M2 subtype, is a serological diagnostic hallmark for PBC, with sensitivity and specificity being $>90-95 \%$ [70, 71]. AMAs recognize 2-oxo acid dehydrogenase complex(2-OADC) located at the inner membrane of the mitochondria, which mainly includes the E2 component of the pyruvate dehydrogenase complex (PDC-E2), branchedchain 2-OADC (BCOADC-E2), 2-oxo-glutaric acid dehydrogenase complex (OGDC-E2), and dihydrolipoamide dehydrogenase binding protein (E3BP). Of note is that the serum level of AMA does not reflect the disease severity of PBC [72].
In clinical practice three methods were commonly used to detect AMA, including immunofluorescence (IIF), enzymelinked immunosorbent assay (ELISA) and Western immunoblot. IIF on fresh frozen rodent kidney, stomach and liver tissues is considered as the initial routine screening [73]. AMA testing with ELISA (AMA-M2), which utilizes all three major autoantigens of AMA(recombinant PDC-E2, BCOADC-E2, and OGDC-E2 proteins) has a higher specificity and sensitivity than IIF $[74,75]$. For those with clinical suspicion of PBC but negative results by IIF and ELISAs, complementary testing with Western immunoblot against mitochondrial antigens could be of value for diagnosis as Western blotting is very specific for AMA detection [76]. Of note, AMA can occasionally be detected in non-PBC subjects, including autoimmune hepatitis (AIH), systemic lupus erythematosus, Sjogren syndrome, chronic hepatitis $\mathrm{C}$, chronic bacterial infection, or even healthy persons, or transiently positive among patients with acute liver failure of any etiology [77].

Anti-nuclear autoantibodies Anti-nuclear autoantibodies (ANAs) are important ancillary diagnostic markers of PBC, which are detectable by IIF in up to $50 \%$ of PBC patients [70]. Certain ANA patterns are highly specific for PBC, including the rim-like membranous pattern targeting gp210 and $\mathrm{p} 62$, and the multiple nuclear dots pattern targeting several proteins including sp100. Meta-analysis showed that anti-gp210 and anti-sp100 have a low sensitivity (15 40\%), but a high specificity (bother greater than 95\%) for AMAnegative PBC [78]. In a large study with more than 4000 tested sera, simultaneous positivity for both anti-sp100 and anti-gp210 has shown a $100 \%$ positive predictive value for PBC irrespective of the AMA status [79].

Recently, antibodies against two novel PBC autoantigens, kelch-like 12 (KLHL12) and hexokinase 1, have been found in 35\% and 22\% of AMA-negative PBC patients, respectively [80]. In addition, anti-promyelocytic leukemia protein (anti-PML), anti-SUMO, anti-Sp140, anti-lamin B receptor and anticentromere all have been found in $\mathrm{PBC}$ patients, but their clinical significance remains elusive [81-84].

\section{Imaging examinations}

Individuals with cholestasis should routinely be examined with ultrasonography. For those with intrahepatic or extrahepatic bile duct dilation on ultrasonography, a diagnosis of $\mathrm{PBC}$ is very unlikely. Instead, magnetic resonance cholangiopancreatography (MRCP), endoscopic retrograde cholangiopancreatography (ERCP), or endoscopic ultrasonography should be considered to rule out other biliary diseases, 


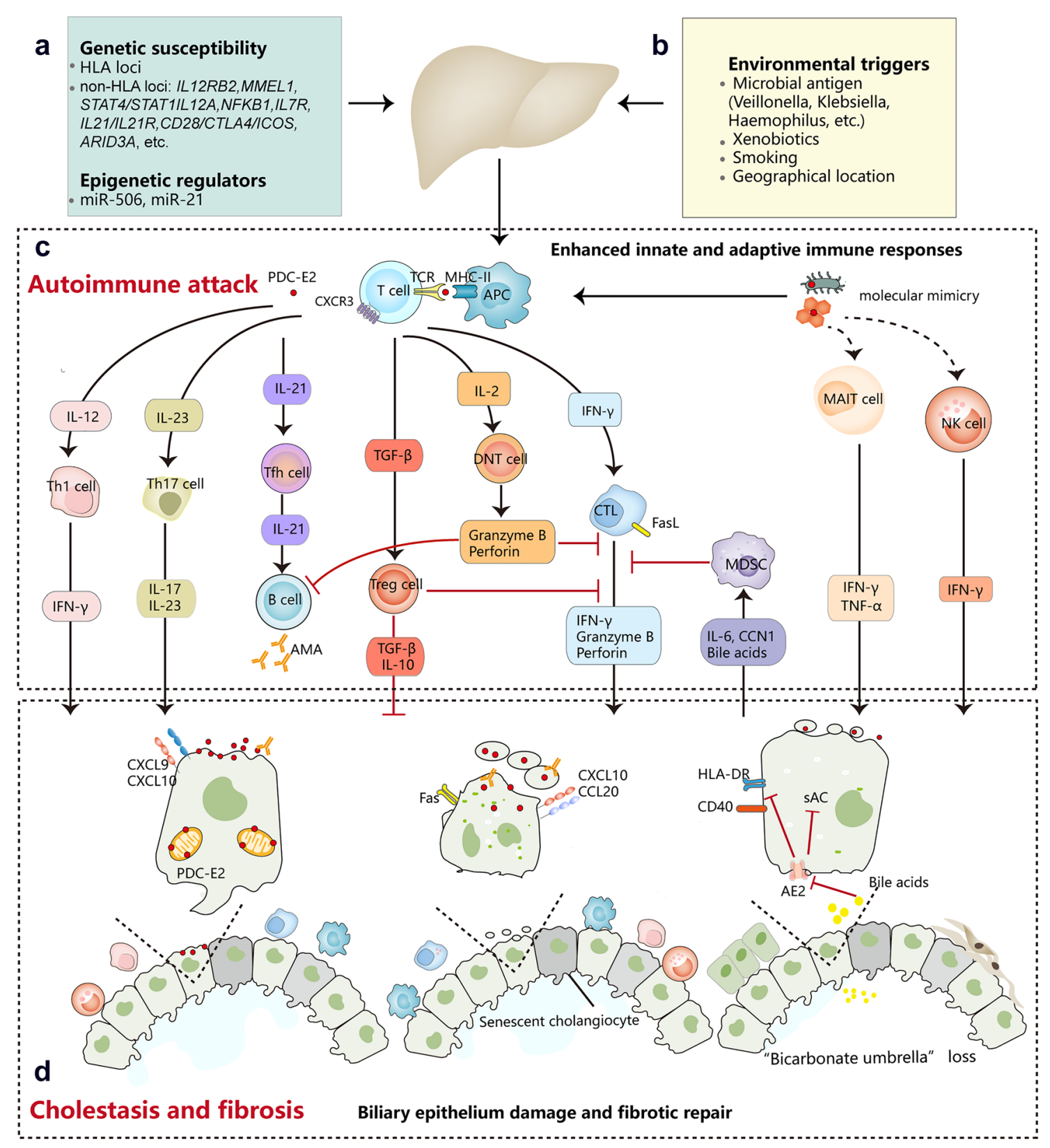

Fig. 1 Pathogenesis of primary biliary cholangitis. PBC is complex and is thought to be caused by the interplay of genetic (A) and environmental factors $(\mathbf{B}, \mathbf{C})$. Exposure to PDC-E2 initiates innate and adaptive immune responses that target biliary epithelial cells and cause inflammation. D Injured cholangiocytes with dysfunctional anion exchanger 2 (AE2) are sensitive to apoptosis and senescence, ultimately leading to cholestasis and liver fibrosis. HLA human leucocyte antigen, miR-506 microRNA 506, miR-21 microRNA 21, PDC$E 2$ the E2 component of the mitochondrial pyruvate dehydrogenase complex, CXCR3 C-X-C motif chemokine receptor 3, APC anti-

including cholelithiasis, inflammation (such as primary sclerosing cholangitis, PSC) or manlignacy [85].

Noninvasive techniques, such as transient elastography (TE) or magnetic resonance elastography (MRE), have been gen presenting cell, $I F N-\gamma$ interferon- $\gamma, T f h$ follicular helper T cell, $A M A$ anti-mitochondrial autoantibody, TGF- $\beta$ transforming growth factor- $\beta$, Treg regulatory T cells, $D N T$ double negative T cell, $C T L$ cytotoxic T lymphocyte, FasL Fas ligand, MDSC myeloid-derived suppressor cell, CCN1 cellular communication network factor 1, MAIT mucosal-associated invariant T cell, $T N F-\alpha$ tumor necrosis factor- $\alpha, N K$ natural killer, $C X C L 9 \mathrm{C}-\mathrm{X}-\mathrm{C}$ motif chemokine ligand 9, CXCL10 C-X-C motif chemokine ligand 10, CCL20 C-C motif chemokine ligand 20, $s A C$ soluble adenylyl cyclase, $A E 2$ anion exchanger 2

evaluated for staging PBC [86, 87]. TE has also been used in longitudinally monitoring the progression of PBC patients [86]. 


\section{Pathological characteristics and histological staging}

Macroscopically, the liver is enlarged in the early stages and can be bile stained. The cirrhotic liver of PBC is generally larger than cirrhosis of other etiology such as viral hepatitis or AIH.

Histologically, PBC is characterized by chronic, nonsuppurative cholangitis that mainly affects interlobular and septal bile ducts (Fig. 3). Focal lesions showing intense inflammatory infiltration and necrosis around bile ducts are termed as "florid duct lesion" and almost pathognomonic for PBC $[88,89]$. The inflammatory infiltration consists of lymphocytes and other mononuclear cells in close contact with the basal membrane of cholangiocytes undergoing necrosis. Bile duct paucity or ductopenia is usually defined as less than $50 \%$ of portal tracts containing bile ducts.

Histologic lesions of PBC are classically divided into four stages [88, 89], according to the degree of bile duct damage, inflammation, and fibrosis. Stage I is characterized by portal inflammation with or without florid bile duct lesions. Epithelioid granulomas are present in some cases, usually in stage I or II. Stage II is characterized by periportal lesions extending into the hepatic parenchyma; the severity of lymphocytic or biliary interface hepatitis is highly predictive of extensive fibrosis development $[90,91]$. Stage III is characterized by a distortion of the hepatic architecture with numerous fibrous septa. Stage IV is defined as cirrhosis with the existence of regenerative nodules.
Recently, Nakanuma et al. proposed new histological assessment criteria for PBC, which consist of both grading (cholangitis activity and hepatitis activity) and staging (scoring of fibrosis, bile duct loss, and deposition of orcein-positive granules) [92]. The novel criteria for histology could stratify the risk for PBC progression and outcomes [93, 94]. More recently, PML expression was found highly specific for histological diagnosis of PBC; therefore, it could be used to discriminate $\mathrm{PBC}$ from other liver diseases including smallduct PSC [95].

\section{Diagnosis criteria}

The diagnosis of PBC is based on the results of biochemical, immunological, radiological, and histological investigations.

Recommendations:

1. The diagnosis of PBC can be established when meeting two or more of the following three criteria: $(\mathrm{I}, 1)$

1. Biochemical evidence of cholestasis based mainly on the elevation of ALP and GGT with the exclusion of extrahepatic biliary obstruction by imaging studies;

2. Presence of AMA or other PBC-specific ANAs including anti-sp100 or anti-gp210;

3. Histologic evidence of non-suppurative destructive cholangitis mainly affecting the interlobular bile ducts.
Fig. 2 Diagnostic flowchart for PBC. $P B C$ primary biliary cholangitis, $A L P$ alkaline phosphatase, GGT gamma glutamyl transferase, $U S$ ultrasonography, $P S C$ primary sclerosing cholangitis, $A M A$ anti-mitochondrial autoantibody, DILI drug induced liver injury

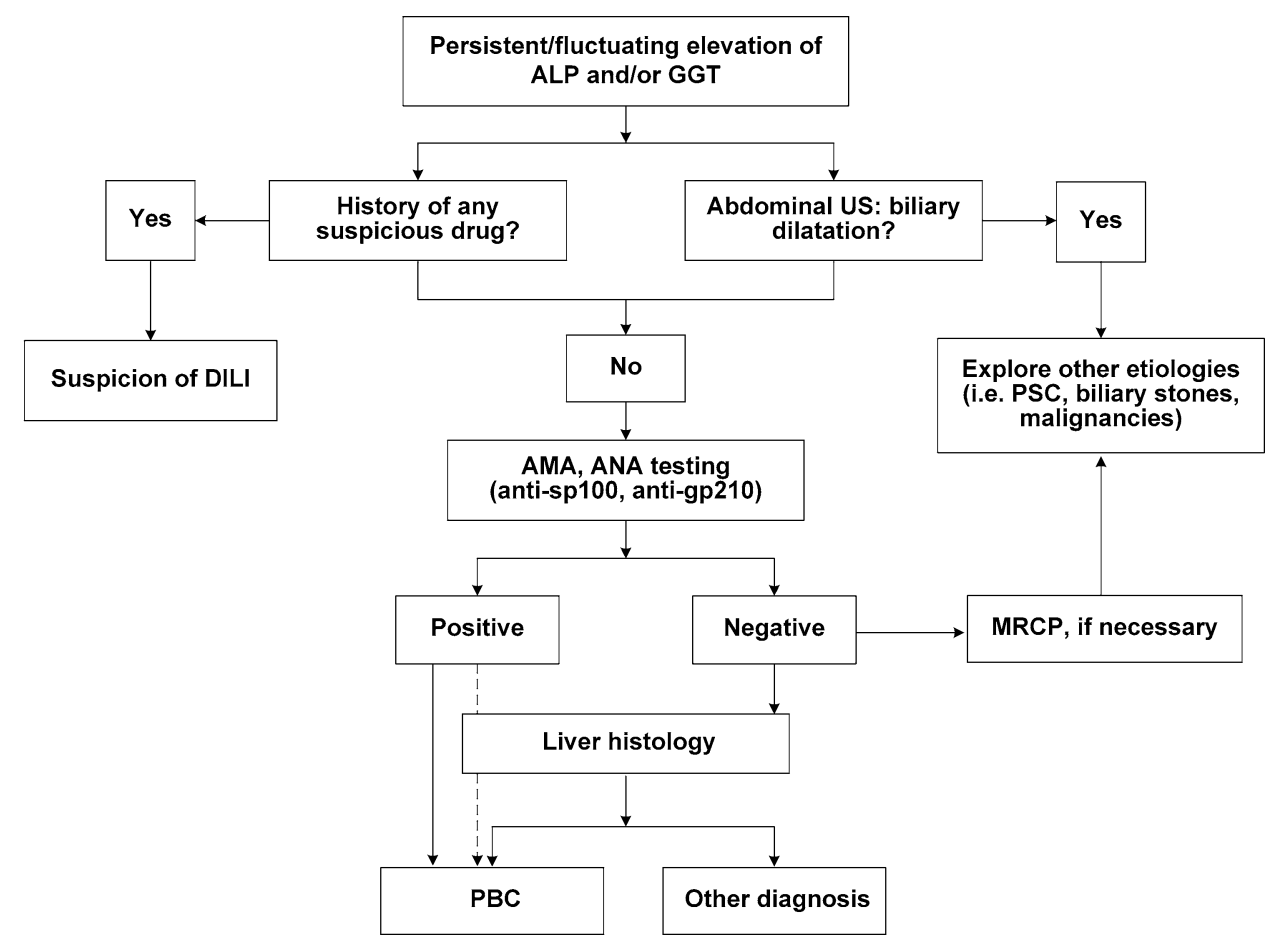




\section{Differential diagnosis}

The differential diagnosis of PBC includes extrahepatic or intrahepatic cholestasis of any other causes (Table 2). Of note is that PSC is characterized by multi-focal bile duct strictures, which can involve intrahepatic, extrahepatic bile ducts, or both. Radiologically mimicking PSC, IgG4-associated sclerosing cholangitis is characterized by high levels of IgG4 in serum along with dense infiltration of IgG4-positive lymphoplasma cells in the tissue.

Langerhans cell histiocytosis (LCH) is a rare systemic disorder characterized by wide-ranging organ involvement and the accumulation of $\mathrm{CD} 1 \mathrm{a}+/$ Langerin $+\mathrm{LCH}$ cells in the tissue.

Sarcoidosis is manifested by non-caseating granulomas within involved organs, most commonly the pulmonary, lymphatic, and hepatic systems.

Amyloidosis is a rare disease that may involve the kidney, heart, liver, and other organs. The clinical manifestations of hepatic involvement by amyloidosis are usually mild, including hepatomegaly and elevation of ALP, but hepatic failure and portal hypertension may develop in some cases.

\section{Management of PBC}

\section{Lifestyle modification}

The possible role of smoking has been implicated in the development and progression of PBC [96]. The alcohol intake (>20 g/d) was usually associated with smoking history and may also contribute to the disease progression [96]. In one study, non-alcoholic steatohepatitis (NASH) and body mass index $\geq 25$ were also associated with severer biliary duct damage and fibrosis in PBC patients, but another study did not confirm this result [97, 98]. In general, lifestyle modifications such as smoking cessation, alcohol abstinence, and body weight reduction would be justified in PBC patients to improve the clinical outcomes.

\section{Recommendation:}

2. In the context of the negative impacts of cigarette smoking, alcohol intake, and obesity on human health, PBC patients should be encouraged to quit smoking, stop alcohol drinking, and keep on ideal body weight. (III, 2).

\section{First-line treatment: UDCA}

UDCA is the treatment of choice and most established therapy for PBC patients, recommended by major national and international clinical practice guidelines [42-44, 99, 100]. Its primary mode of action is to exert the choleretic effect and protect hepatocytes and cholangiocytes against the cytotoxicity of hydrophobic bile acids. The optimal dosage of
UDCA is $13 \sim 15 \mathrm{mg} / \mathrm{kg}$ per day in a single or divided oral doses. Studies show that low-dose UDCA $(5 \sim 7 \mathrm{mg} / \mathrm{kg}$ per day) is less effective, but high-dose UDCA ( $23 \sim 25 \mathrm{mg} / \mathrm{kg}$ per day) does not bring more benefits [101].

Tauroursodeoxycholic acid (TUDCA) is a taurine conjugated form of UDCA with higher hydrophilicity. TUDCA $750 \mathrm{mg} /$ day showed similar biochemical efficacy and safety profile to UDCA $750 \mathrm{mg} /$ day in a multicenter randomized clinical study [102].

Many randomized controlled trials and meta-analyses demonstrated that UDCA can improve biochemical variables [103-105], halt the disease progression [106, 107] and prolong the liver transplant-free survival [108, 109]. UDCA is safe and well-tolerated in PBC patients. The frequently reported side effects are diarrhea, flatulence, weight gain, and pruritus aggravation. These side effects are generally minor and do not require therapy withdrawal. Despite its excellent safety profile, a recent study showed $11 \%$ of the UDCA-treated patients showed poor adherence to the therapy [110]. Young age and male sex were independently associated with poor adherence.

\section{Recommendation:}

3. It is recommended that oral UDCA $(13 \sim 15 \mathrm{mg} / \mathrm{kg} /$ day) should be standard therapy for all PBC patients. UDCA treatment should be continued for prolonged periods, and compliance to therapy should be checked $(\mathrm{I}, 1)$.

\section{Criteria of biochemical response to UDCA}

Unfortunately, about $30-40 \%$ of PBC patients show insufficient biochemical responses to UDCA and remain at risk for disease progression to advanced stages, including cirrhosis [111-114]. Several criteria of biochemical response were proposed to help the risk stratification of $\mathrm{PBC}$ patients and to identify those who need second-line therapy (Table 3) [111, 115-121], which were summarized in a recent review [122]. Among many, Paris I [111] and Paris II criteria [121] are well-validated and widely used criteria of biochemial response in patients with advanced PBC (stage III-IV) and early PBC (stage I-II), respectively.

Recently, the two new continuous scoring systems, the GLOBE score [123] and the UK-PBC score [124], have been proposed based on multicenter studies with large number of patients included. GLOBE and UK-PBC scores are not only the response criteria but also important prognostic scores, which provided more accurate and individualized survival information than the existing models. These two scoring systems have recently been validated in a large international, multicenter PBC cohort, showing excellent prognostic performance [125].

Most studies demonstrated that ALP and total bilirubin are the two most important variables in evaluating UDCA response [126, 127]. Additionally, while most models assess 

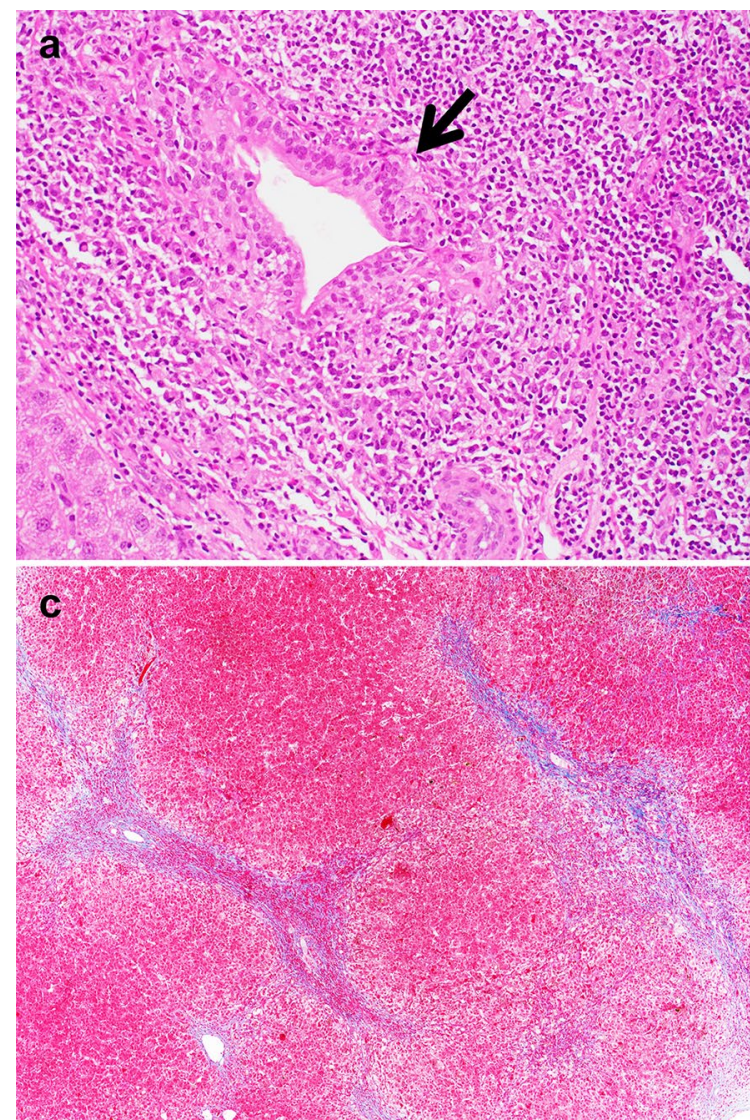

Fig. 3 Typical histological features of PBC in different stages. a Stage I: chronic non-suppurative destructive cholangitis (arrow, H\&E, 200×). b Stage II: ductular reaction with periportal necroinflammo-

biochemical response after 12 months of UDCA treatment, some reports suggest that evaluation after six months of UDCA treatment may have equivalent predictive utility $[114,118]$.

Prediction of response to UDCA is attempted even before the commencement of treatment. Based on two large-scale cohorts of PBC patients in the UK and Italy, Carbone et al. developed and validated a UDCA response score, consisting of bilirubin, ALP, transaminase, age, and lag time from diagnosis to treatment [128]. This score was also validated in a Japanese cohort [129]. Pretreatment prediction may help physicians identify patients with baseline characteristics conferring a high risk of incomplete response to UDCA and initiate a de novo combination of UDCA and another agent.

Recommendation:

4. It is recommended that evaluating all PBC patients for the biochemical response with appropriate criteria after 6 months of UDCA treatment (III, 1), or 12 months of UDCA treatment (II, 1)
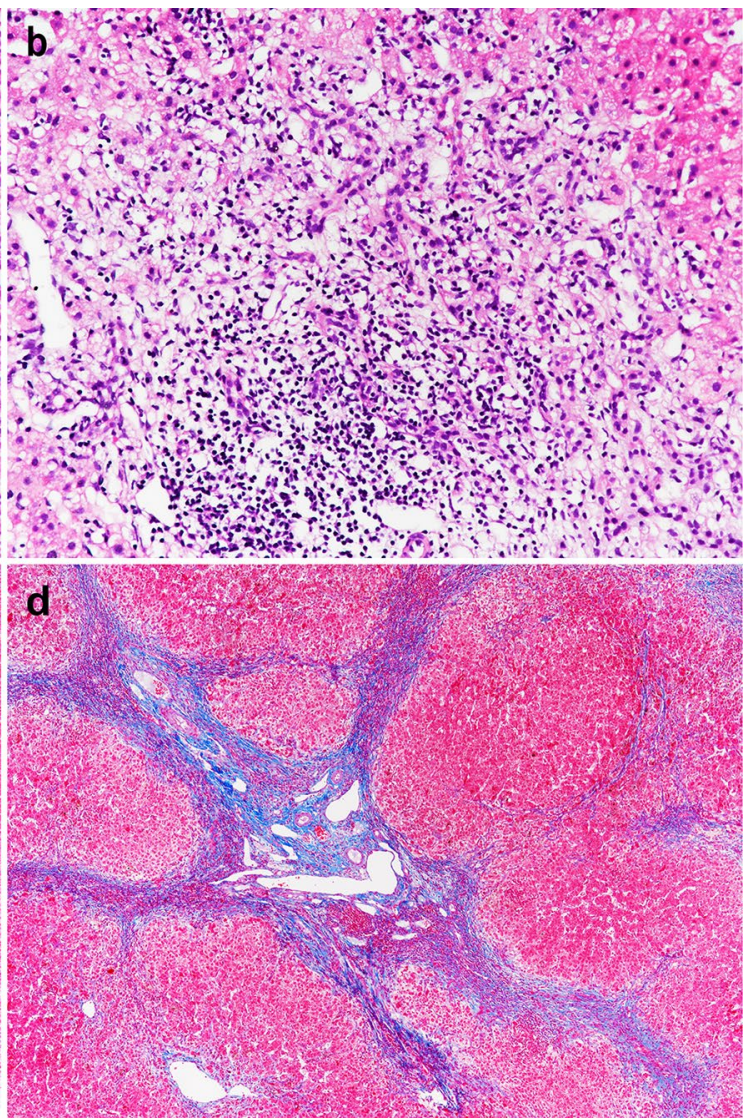

tory activity (H\&E, 200×). c Stage III: multiple portal-portal bridging fibrosis (Trichrome, 40×). d Stage IV: biliary cirrhosis with nodule formation (Trichrome, 40×)

\section{Second-line therapy for suboptimal responders to UDCA}

There is no consensus on therapies for patients with insufficient biochemical response to UDCA. In several clinical trials, obeticholic acid (OCA), fibrates, and budesonide proved to be effective and could be considered as secondline therapy for patients with insufficient UDCA response, but the long-term result needs further verification. Figure 4 showed the risk-based approach for managing PBC patients.

\section{Second-line therapies approved in some regions of the world}

Obeticholic acid OCA has been approved as second-line therapy for PBC in the United States and Europe. OCA is a semi-synthetic hydrophobic bile acid analog that is highly selective for the farnesoid $\mathrm{X}$ receptor (FXR), a nuclear receptor abundantly expressed in the liver and enterocytes. In addition to directly regulating genes involved in the 
Table 2 Differential diagnosis of PBC

\begin{tabular}{ll}
\hline Intrahepatic cholestasis & Extrahepatic cholestasis \\
\hline Hepatocyte-associated & Cholelithiasis \\
Autoimmune hepatitis & Inflammatory stenosis \\
Alcoholic liver disease & Malignancy \\
Drug-induced liver disease & \\
Bile duct-associated & \\
Primary sclerosing cholangitis & \\
Secondary sclerosing cholangitis & \\
IgG4-associated sclerosing cholangitis & \\
Vascular diseases & \\
Sinusoidal obstruction syndrome & \\
Budd-Chiari syndrome & \\
Congestive hepatopathy & \\
Miscellaneous & \\
Sarcoidosis & \\
Hepatic amyloidosis & \\
Langerhans cell histiocytosis &
\end{tabular}

metabolism of bile acid synthesis, FXR signaling impacts inflammation, metabolic regulation, and liver fibrosis.

In a multicenter, double-blind phase II clinical trial, three doses of OCA $(10,25$, and $50 \mathrm{mg} /$ day $)$ were added to UDCA for PBC patients with suboptimal response to UDCA (ALP > 1.5 $\times$ ULN). After three months, all three groups receiving OCA had more profound reductions in ALP level than the placebo group; moreover, in the 12-month open-label extension period, ALP levels continued to decrease [130]. In another randomized phase II clinical trial of OCA monotherapy in PBC patients who were UDCA-naiive or not taking UDCA for more than 3 months, ALP and other biochemical markers (GGT, ALT, conjugated bilirubin and $\operatorname{IgM}$ ) were reduced in both OCA $10 \mathrm{mg}$ and OCA $50 \mathrm{mg}$ groups compared with the placebo group at the end of 3-month double-blinded phase, and the biochemical improvement was also observed at the end of 6-year openlabel extention treatment [131].

In a double-blind phase III clinical trial from the PBC OCA International Study of Efficacy (POISE) group, after 12 months of OCA therapy (add-on to UDCA or as monotherapy) nearly half of the PBC patients who were prior biochemical non-responders or intolerance to UDCA achieved better biochemical improvement than the placebo group [132]. In a recent 3-year interim analysis from the 5-year open-label extension of the phase III POISE trial, ALP and total bilirubin were significantly decreased after 12 months and 48 months of OCA treatment compared to baseline [133].

Obeticholic acid was generally well tolerated after longterm follow-up, with pruritus $(77 \%)$ and fatigue $(33 \%)$ being the most common adverse events in phase III POISE trial [133]. Of note, the exacerbation of pruritus was dosedependent, leading to treatment discontinuation in $15 \%$
(OCA $10 \mathrm{mg}$ ) to $38 \%$ (OCA $50 \mathrm{mg}$ ) of patients [131]. Moreover, patients treated with OCA exhibit a reduction of high-density cholesterol [131, 132]. It is still controversial if the reduction of high-density cholesterol increases the risk of cardiovascular events, although no serious adverse events were observed based on current results. In September 2017, the Food and Drug Administration of the United States released a warning that the use of OCA in PBC patients with decompensated cirrhosis (Child-Pugh-Turcotte B and C) was associated with clinical worsening or even death. Therefore, the use of OCA in PBC patients with decompensated cirrhosis was not recommended.

\section{Recommendation:}

5. It is recommended that OCA (starting at $5 \mathrm{mg} /$ day, increasing to $10 \mathrm{mg} /$ day after 6 months if tolerated well) be added to UDCA therapy for PBC patients (non-cirrhotic or cirrhosis with Child-Pugh-Turcotte A) and an inadequate response to UDCA or used as monotherapy in those intolerant to UDCA. Potential risks and adverse events of OCA should be discussed in detail with the patient, carefully evaluated and appropriately monitored. $(\mathrm{I}, 1)$

\section{Second-line therapies as off-label use}

Fibrates (Fenofibrate and Bezafibrate) Reports from the USA, Europe, and Asia demonstrated good efficacy of fenofibrate in PBC patients with suboptimal response to UDCA [134, 135]. Meta-analysis indicated that fenofibrateUDCA combination therapy was more effective in decreasing ALP, GGT, IgM, and triglyceride levels than UDCA monotherapy, but it did not reduce ALT or improve pruritus [136]. Adverse events did not appear to increase in patients treated with fenofibrate-UDCA combination. However, possible liver and renal impairment in PBC patients, especially those with decompensated cirrhosis, need to be closely monitored [137].

Bezafibrate seems to have better efficacy than fenofibrate, but head-to-head comparison is still lacking. Studies showed that bezafibrate combined with UDCA could significantly decrease ALP, GGT, ALT, IgM, triglyceride, and total cholesterol levels [138, 139]. In 2018, a randomized, placebo-controlled phase III trial in PBC patients showed that bezafibrate combined with UDCA for 24 months achieved a higher rate of complete biochemical response than placebo plus UDCA in patients with incomplete response to UDCA monotherapy [140]. A recent Japanese study also reported that adding bezafibrate to UDCA in 118 PBC patients unresponsive to UDCA monotherapy resulted in improvements not only in liver biochemistry, UK-PBC, and GLOBE scores, but also in the long-term prognosis [141].

Additonally, recent studies showed that bezafibrate addon treatment can completely or partially relief itching for PBC patients with suboptimal response to UDCA [139, 
Table 3 Evaluation of response to UDCA therapy in patients with PBC

\begin{tabular}{lcl}
\hline UDCA-response criteria & Time (months) & Definition of response \\
\hline Barcelona [115] & 12 & $>40 \%$ decrease or normalization of ALP \\
Mayo [116] & 6 & ALP $<2 \times$ ULN \\
Paris I [111] & 12 & ALP $\leq 3.0 \times$ ULN and AST $\leq 2.0 \times$ ULN and normalization of bilirubin \\
Rotterdam [117] & 12 & Normalization of abnormal bilirubin and/or albumin \\
Ehime [118] & 6 & $\geq 70 \%$ decrease or normalization of GGT \\
Toronto [119] & 24 & ALP $\leq 1.67 \times$ ULN \\
Paris II [121] & 12 & ALP and AST $\leq 1.5 \times$ ULN and normalization of bilirubin \\
Risk scoring systems & 12 & Included parameters \\
$\quad$ GLOBE [123] & 12 & Age at diagnosis. ALP, bilirubin, albumin and platelet count at 12 month \\
UK-PBC [124] & & Baseline albumin and platelet count \\
& & ALP, bilirubin and AST (or ALT) at 12 month \\
\hline
\end{tabular}

$U D C A$ ursodeoxycholic acid, $A L P$ alkaline phosphatase, $U L N$ upper limit of normal, $A S T$ aspartate aminotransferase, $A L T$ alanine aminotransferase

140]. Moreover, a phase III linical trial found a $>50 \%$ reduction of the intensity of pruritus score (VAS) in $55 \% \mathrm{PBC}$ patients with moderate to severe pruritus after 21 days treatment of bezafibrate [142]. However, it has been reported that the bezafibrate-UDCA combination therapy was associated with more frequent adverse events than the UDCA monotherapy, including elevation of the serum creatinine levels and myalgia, polydipsia, aggravated pruritus, arthritis, leg edema, and gastrointestinal discomfort [138, 143].

\section{Recommendation:}

6 . It is recommended that bezafibrate ( $400 \mathrm{mg} /$ day) or fenofibrate (200 mg/day) could be added to UDCA for patients with an inadequate response to UDCA monotherapy. Adverse events should be closely monitored, especially in cirrhotic PBC patients. (I, 1).

Budesonide Budesonide is the second generation of corticosteroids with high first-pass metabolism within the liver, therefore, it has fewer systemic side effects than conventional glucocorticosteroids. Two early reports of the multi-center prospective randomized study showed that adding budesonide (6-9 mg/day) to UDCA (15 mg/kg/day) in PBC patients exhibited better biochemical and histological improvement than continue UDCA monthotherapy [144, 145]. However, in a recent small scale randomized clinical trial, budesonide (9 mg/day) adding to UDCA (12 16 mg/kay/day) for 36 months achieve a better biochemical response but failed to achieve superior histological improvement in $\mathrm{PBC}$ patients with suboptimal response to UDCA monotherapy [146].

In summary, combination therapy with budesonide and UDCA might benefit non-cirrhotic PBC patients, but its efficacy on long-term clinical outcomes including mortality and requirement of liver transplantation still need further investigation. Of note is that significant increases in budesonide plasma levels were observed in late-stage PBC and were associated with severe side effects, including portal thrombosis. Therefore, the use of budesonide is not recommended for patients with cirrhosis [147].

\section{Recommendation:}

7. Budesonide (6-9 mg/day) might be added to non-cirrhotic PBC patients with suboptimal response to UDCA. (II, 2)

\section{Management of symptoms and complications}

\section{Pruritus}

Pruritus is one of the characteristic symptoms of cholestasis and results in impaired health-related HRQoL in PBC

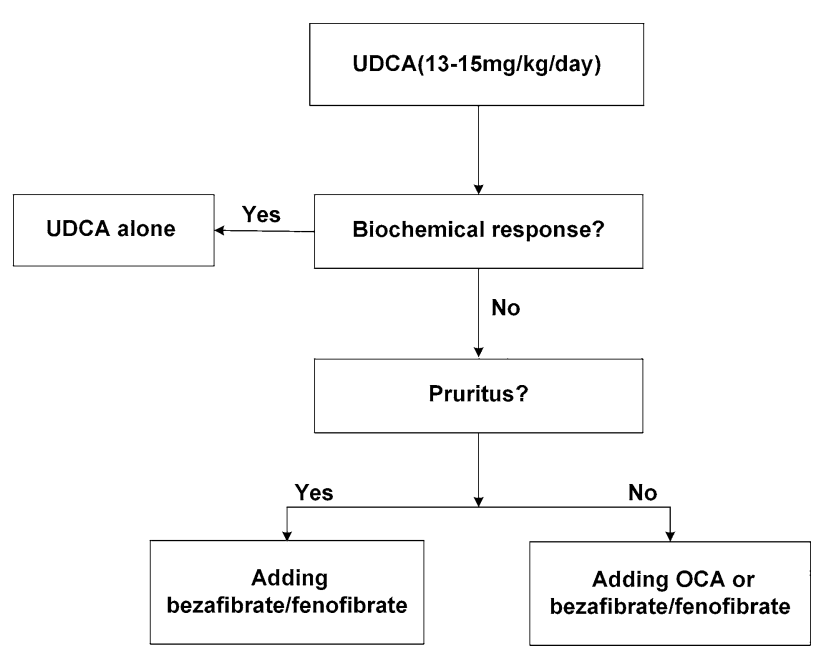

Fig. 4 Risk-based approach for PBC patients. UDCA ursodeoxycholic acids, $O C A$ Obeticholic acid 
patients. Although several candidate pruritogens, including lysophosphatidic acid, autotaxin, bile acids, bilirubin and endogenous opioids, have been proposed [148], the pathogenesis of pruritus has not been fully understood. A recent research found a novel bile acid receptor called MRGPRX4, which might be a promising therapeutic target for pruritus [149].

To date, cholestyramine is the first-line therapy for pruritus caused by cholestasis. The recommended dose is $4-16 \mathrm{~g} /$ day. The major side effects include abdominal bloating, constipation, and interference with the absorption of other drugs such as UDCA [150]. A four-hour interval is required between taking cholestyramine and other drugs.

If the patients are intolerant to cholestyramine, rifampicin could be the second choice. The recommended dose for rifampicin is $150 \mathrm{mg}$ twice a day. For the patients without adequate response, the dose could be increased to $600 \mathrm{mg} /$ day. Two meta-analysis indicated that rifampicin could effectively relieve itching caused by cholestasis [151, 152]. However, rifampicin could cause severe liver injury, hemolytic anemia, and renal damage and affect the metabolism and activity of other drugs [153-155]. Therefore, it is necessary to monitor the side effects of rifampicin.

Opioid antagonists could be considered as the third choice. Two randomized clinical trials and followed studies indicated that intravenous injection or oral administration of naloxone is effective for obstinate pruritus [151]. Naloxone should start from a low dose and slowly escalated to the optimal dose. The main adverse reactions were withdrawal symptoms. Nalfurafine hydrochloride, a selective kappa-opioid receptor agonis has been approved for intractable pruritus in patients with PBC in Japan [156]. As the 5-hydroxytryptamine system might be involved in the pathogenesis of pruritus, ondansetron and sertraline are also used to treat pruritus. To relieve severe or intractable pruritus, liver transplantation could be considered.

Currently, the efficacy and safety of linerixibat, a novel compound inhibiting ileal bile acid transporter (IBAT), is being evaluated for intracable pruritus in clinical trials of PBC patients. IBAT could diminish the total bile acid pool by inhibiting enter-hepatic circulaion, thereby reducing the pruritogens retended in bile acids. In the phase 2 a study, 14 days of linerixibat treatment could reduce the pruritus severity [157], which has been confirmed by an international phase $2 b$ trial [158]. It is generally well tolerated, although mild to moderate diarrhea occurred due to retention of bile acid in the colon.

\section{Recommendations:}

8. It is recommended that cholestyramine ( $4-16 \mathrm{~g} / \mathrm{day})$ as the first-line therapy for pruritus. To avoid interference with the absorption, take other medications including UDCA at least $1 \mathrm{~h}$ before or 4 to $6 \mathrm{~h}$ after taking cholestyramine. (II, 2)
9. Rifampicin (150-300 mg twice a day) can be used as second-line therapy for pruritus with close monitoring of side effects. (II, 2)

\section{Vitamin D deficiency and osteoporosis}

Previous studies reported that vitamin D deficiency was associated with the severity of chronic liver diseases [159]. EASL nutritional guidelines recommend supplement vitamin D orally in cirrhotic patients with vitamin D levels $<20 \mathrm{ng} /$ $\mathrm{ml}$, to reach serum vitamin $\mathrm{D}(25(\mathrm{OH}) \mathrm{D})>30 \mathrm{ng} / \mathrm{ml}$ [159]. For PBC patients, studies showed that vitamin D deficiency was common, especially in patients with more advanced disease and suboptimal response to UDCA therapy [160-162]. For perimenopausal and postmenopausal women, sufficient calcium (1000-1500 mg/day) and vitamin D (1000 IU/day) in the diet or as supplements are recommended if they have no history of renal stones [42].

The mechanisms for metabolic bone diseases (bone loss and osteoporosis) in PBC patients are complicated, involving the defect of absorption of fat-soluble vitamins and the direct effect of cholestasis on bone metabolism. The risk of fracture in PBC patients is two times higher than that in the healthy population. Supplements of calcium and vitamin D are recommended, with particular care in patients with a femur $T$ score lower than - 1.5 [163].

A meta-analysis of six randomized clinical trials provided insufficient evidence to claim or refute a benefit for bisphosphonates (alendronate, etidronate, ibandronate) in treating PBC-related osteoporosis [164]. However, a recent randomized clinical trial showed that either weekly alendronate or monthly ibandronate treatment could improve bone mass in patients with PBC [165].

Bisphosphonates are generally well-tolerated, and the potential side effects include gastroesophageal irritation, osteonecrosis of the jaw, musculoskeletal pain, and atrial fibrillation. Bisphosphonates are not recommended for people with severe impairment of renal function or hypocalcemia. People with specific problems of the esophagus may not be able to take the oral tablets.

So far, hormone replacement therapy in women with PBC is not supported by reliable evidence [166]. Recently, a report comfirmed the efficacy and safety of denosumab, a fully human monoclonal antibody against the receptor activator of nuclear factor-kappaB ligand (RANKL), for osteoporosis in patients with PBC [167].

\section{Recommendations:}

10. It is recommended that all PBC patients should be evaluated for serum vitamin D status. (II, 2)

11. It is recommended that all PBC patients should be evaluated for osteoporosis, especially in postmenopausal women. (III, 2) 
12. Patients should intake enough calcium (1000-1500 mg/day) and vitamin D (1000 IU/day) in the diet or as supplements if needed, according to local practice. (III, 2)

13. Bisphosphonates (alendronate $70 \mathrm{mg}$ weekly or ibandronate $150 \mathrm{mg}$ monthly or others) can be considered in patients with osteoporosis. Bisphosphonates should be used with caution in patients with esophageal varices, and the side effects should be monitored in all patients. (III, 2)

14. Data on denosumab efficacy in PBC patients with osteoporosis is very limited in Asia Pacific region, therefore, a clear recommendation cannot be made (or supported). (III, 2)

\section{Fatigue}

No effective therapy for fatigue is available at this moment. Though multiple candidates have been tested, such as UDCA, fluoxetine, colchicine, methotrexate, ondansetron and S-ademetionine, only modafinil exhibits promising results. An observational study indicated that modafinil could attenuate fatigue in PBC patients caused by excessive daytime sleepiness and improve the Epworth Sleepiness Scale and PBC-40-Quality of Life [168].

The side effects of modafinil include insomnia, nausea, headache, and nervousness. More evidence is required to verify the efficacy of modafinil. The physicians should also pay attention to other factors associated with fatigue, such as anemia, hypothyroidism, depression, and sleep disorders.

\section{Recommendation:}

15. No specific medical therapy is available for fatigue. Treating co-existent conditions such as anemia, extra-hepatic autoimmune disease, sleep disturbance, and depression are recommended to manage fatigue. (III, 2)

\section{Portal hypertension}

Patients with $\mathrm{PBC}$ progress into portal hypertension as a result of biliary cirrhosis. A screening esophagogastroduodenoscopy (EGD) should be performed in patients with cirrhotic features at the time of the diagnosis. However, esophageal varices can develop early in the disease course, even before the establishment of cirrhosis [169]. Nodular regenerative hyperplasia may play a role in portal hypertension development of early-stage PBC patients [66]. The Baveno-VI criteria (LSM by TE $<20 \mathrm{kPa}$ and platelet count $\left.>150 \times 10^{9} / \mathrm{L}\right)$ can be used to identify patients who may not need screening EGD. One study showed that this strategy could avoid $39 \%$ of screening EGD with a false negative rate of $0 \%$ [170]. Nonselective beta-blockers and/or endoscopic band ligation is indicated in patients with large esophageal varices or variceal hemorrhage.

Recommendation:
16. Patients with features of portal hypertention (ie. splenomegaly, thrombocytopenia) should be screened for gastroesophageal varices. (II, 2)

\section{Hepatocellular carcinoma}

The reported incidences of $\mathrm{PBC}$-related $\mathrm{HCC}$ range from 2.4 to 6.6 cases per 1000 patient-years, which is two times higher in males than that in females [67, 68, 171-173]. A recent meta-analysis showed that the PBC-related HCC incidence was 5.77 per 1000 person-years in Asia, which was similar to that in North America (5.10 per 1000 personyears), but higher than that in Europe(2.67 per 1000 personyears) [174].

As reported, male sex and advanced histological stage independently associated with the development of HCC [67, 68, 171-173]. In addition, an international cohort study showed that biochemical non-response at one year of UDCA treatment (Paris-II not fulfilled) significantly increased the future risk of HCC [172]. Other risk factors associated with $\mathrm{HCC}$ in $\mathrm{PBC}$ including older age, any signs of portal hypertension, thrombocytopenia, past HBV infection, diabetes, obesity and alcohol consumption, as summurized by two recent reviews [67, 69].

Taken together, close monitoring for HCC development is strongly recommended for high-risk patients with PBC, such as males, patients with advanced-stage disease, and non-responders to UDCA.

\section{Recommendation:}

17. Close monitoring of HCC is strongly recommended for males, patients with advanced-stage disease, and nonresponders to UDCA. (II, 2)

\section{Liver transplantation}

Liver transplantation (LT) should be considered in PBC patients who have progressed to decompensated cirrhosis (ascites, variceal hemorrhage, or hepatic encephalopathy), with a model for end-stage liver disease (MELD) score $>15$, or with a Mayo Risk Score $>7.8$ [43, 175, 176]. Severe intractable pruritus that heavily compromises the HRQoL is an exceptional indication for transplantation.

The long-term post-tranplant survival is relatively optimistic in PBC patients, with a 5-year survival rate of 80-85\% [177-179]. The 5-, 10-, and 15- year post-transplant recurrence occurs approximately in $22 \%, 21-37 \%$, and $40 \%$ of liver allografts, respectively, with a median time range of 3-6.9 years [180, 181]. The diagnosis of $\mathrm{PBC}$ recurrence is based on histological features (granulomatous cholangitis and/or florid duct lesions) and biochemical abnormalities [178, 182], since AMA may remain positive after LT even without PBC recurrence. Younger age, use of tacrolimus, 
and biochemical cholestasis after LT were related to PBC recurrence [180].

Previous studies reported that PBC recurrence did not significantly compromise the long-term outcomes. However, a recent large-scale retrospective cohort study demonstrated that PBC recurrence significantly compromised graft and patient survival rates [180]. Prophylactic use of UDCA is safe and effective in preventing PBC recurrence after liver transplantation [183].

\section{Recommendations:}

18. It is recommended that liver transplantation should be considered in patients with decompensated cirrhosis, MELD $\geq 15$, Mayo Risk Score $>7.8$, or severe, intractable pruritus. (II, 1)

19. Post-transplant UDCA treatment is safe and effective in improving liver function tests and prevent $\mathrm{PBC}$ recurrence. (II, 1)

\section{Special conditions}

\section{PBC with AIH features (formerly known as PBC-AIH overlap syndrome)}

$\mathrm{PBC}$ and $\mathrm{AIH}$ are nosological entities characterized by different histological and serological phenotypes. They can coexist in the same patients with either a sequential or a simultaneous presentation. As the most common overlap form in autoimmune liver diseases, the prevalence of PBC with AIH features is approximately $5 \sim 15 \%$ of all PBC patients $[184,185]$. Similarly, AMA can also be detected in 5-35\% of patients with well-established AIH [71]; whether these patients will develop typical PBC is till to be defined [186].

The explicit clinical or pathological definition of $\mathrm{PBC}$ with AIH features is still lacking, although the "Paris Criteria" (1998) are frequently used in clinical practice [187]. According to these criteria, to diagnose the PBC with AIH features, the patients must meet at least two of each three criteria of PBC and AIH. For PBC: (1) serum ALP levels at least two times ULN or serum GGT levels at least five times ULN; (2) the presence of AMA and/or AMA-M2; (3) a liver biopsy showing florid duct lesions. For AIH: (1) ALT levels at least five times ULN; (2) serum IgG levels at least two times ULN or the presence of anti-smooth muscle antibody (ASMA); (3) a liver biopsy showing moderate/severe interface hepatitis (mandatory).

However, ASMA positivity is less frequent, and the serum IgG levels are seldom above $2 \times \mathrm{ULN}$, especially in the Asia-Pacific region $[188,189]$. Thus, the "Paris Criteria" are probably too stringent for diagnosing the $\mathrm{PBC}$ with $\mathrm{AIH}$ features in this region. A study from China showed that the serum IgG levels $\geq 1.3 \times$ ULN had a $60 \%$ sensitivity and a 97\% specificity for PBC with AIH features, which is more sensitive than "Paris Criteria" (IgG levels $\geq 2 \times$ ULN) [190].

Autoantibodies profile were also explored as potential diagnostic markers for PBC with AIH features. Muratori et al. found that stimultaneous positivity for AMA and antidsDNA had a 98\% specificity for diagnosis of PBC with AIH features [191]. In line with this, a recent study demonstrated that anti-dsDNA could be the diagnostic marker of PBC with AIH features, whereras other autoantibodies including antip53, Ro52/TRIM21, anti-KLHL-12 and anti-HK-1 were not significantly associated with PBC with AIH features [192].

Of note, authors from Europe and the US strongly discourage using the AIH scoring system (International Autoimmune Hepatitis Group; IAIHG 1999) or the simplied score (IAIHG 2008) for diagnosing PBC with AIH features [184, 193-195].

Patients with PBC with AIH features have poorer outcomes than those with AIH or PBC alone [196]. A nationwide study from Japan suggested that the simplified AIH scoring system (IAIHG 2008) was beneficial for selecting patients who require corticosteroids administration [197]. For these patients, two therapeutic approaches could be considered. One is to treat the patients with UDCA for 3-6 months, and add immusuppresive therapy if the levels of ALT/AST and IgG are still not improved. Another approach is to start UDCA and immusuppresive therapy simultaneously if the evidence for PBC with AIH features is strong. Studies showed that corticosteroids with or without azathioprine, or second-line immunosuppressants (i.e., mycophenolate mofetil, tacrolimus, and cyclosporine A) added to UDCA is useful to increase the response rates and improve the prognosis [198, 199].

\section{Recommendations:}

20. The diagnosis of PBC with AIH features could be made in $\mathrm{PBC}$ patients if two of the three following criteria are met: (1) moderate/severe interface hepatitis in liver histology (mandatory); (2) serum ALT/AST more than 5 times ULN; and (3) IgG level more than 1.3 times ULN or the presence of ASMA. (III, 2)

21. mmunosuppressive agents (including corticosteroid with or without azathioprine or mycophenolate mofetil) could be used as add-on therapy to UDCA, or de novo combination therapy with UDCA. (III, 2)

\section{AMA-negative PBC}

About 5\% of PBC patients are negative for AMA [70, 71]. AMA-negative PBC patients tend to have lower IgM levels and higher titers of PBC-specific ANA (anti-gp210 and/or anti-sp100) than AMA-positive PBC patients [200]. Most studies suggested that the clinical presentation, liver histology and clinical course of AMA-negative PBC were nearly 
identical to AMA-positive PBC [200, 201]. However, some studies indicated that AMA-negative $\mathrm{PBC}$ was associated with more severe bile duct damage on histology and worse clinical outcomes [202]. [203].

Therefore, to avoid undue delay of the treatment, liver biopsy is recommended for this kind of patients to confirm the diagnosis of AMA-negative PBC and to exclude the coexistence of AIH or NASH.

\section{Recommendations:}

22. It is recommended that liver biopsy should be performed on patients who present otherwise unexplained cholestatic liver biochemistry and negative for AMA, antigp210, or anti-sp100 to confirm the diagnosis of PBC. (III, 2)

\section{Isolated AMA positivity}

Studies demonstrated that some individuals with AMA positivity and normal serum ALP levels had shown no clinical evidence of PBC [204-206]. Dahlqvist et al. reported that only 1 out of 6 AMA-positive patients with normal serum ALP levels would progress to PBC during follow-up for five years [205]. Gulamhusein et al. also found that none of the first-degree relatives of PBC patients who were AMA-positive and with normal ALP at baseline developed PBC during follow-up [206]. In line with this finding, several other studies showed that the prevalence of AMA positivity in healthy subjects was higher than the prevalence of PBC [207-209].

However, a recent single-center study from China showed that more than $80 \%$ of patients with normal ALP and positive AMA had histological evidence of PBC [210]. Similar result was also reported from a multi-center Swiss study [211]. Histologically proven PBC patients who had AMA positivity and with normal ALP had significantly higher ELISA-determined AMA titers, higher level of ALP (within normal range), and elevated IgM than individuals with positive AMA only [210]. Therefore, regular following-up and timely liver biopsy are recommended for these patients since prompt initiation of UDCA therapy may be beneficial.

\section{Recommendation:}

23. AMA reactivity alone is not sufficient to diagnose PBC. AMA-positive patients with normal serum liver tests should be followed up with an annual biochemical reassessment for the presence of liver disease. A liver biopsy may be considered in selected patients (eg. patients with elevated IgM, high titer of AMA, or ALP close to ULN) to identify preclinical PBC. (III, 2)

\section{Pregnancy}

Most studies reported that maternal and fetal outcomes were good for pregnant women with PBC [212-214]. However, cirrhotic PBC patients have a higher risk of maternal and fetal complications, therefore, they may need special counseling.

UDCA is widely used in patients with intrahepatic cholestasis of pregnancy and is presumed to be safe during the second and third trimester [215-217]. Studies did not show any unexpected side effects in pregnant women with $\mathrm{PBC}$ or PSC who received UDCA during the first trimester [213, $214,218]$. However, information on this issue still remains too scarce to give a specific recommendation.

There is also a paucity of data on the safety of UDCA during breastfeeding. Rudi et al. firstly reported that treatment of UDCA $750 \mathrm{mg} /$ day did not result in appearance of UDCA in the breast milk in a PBC patient at breastfeeding [219]. In another case [220], UDCA treatment was initiated at $7.5 \mathrm{mg} / \mathrm{kg} /$ day and gradually increased to $25 \mathrm{mg} / \mathrm{kg} / \mathrm{day}$, with no effects on the bile acid content in the breast milk. In light of published cases there are no severe side effects among babies whose mothers continued UDCA during breastfeeding [213]. These results suggested that it appears safe to receive UDCA during breastfeeding.

Recommendations:

24. Pregnancy can be advised in PBC patients at childbearing age. Patients with features of cirrhosis should be well informed about the possible maternal and fetal complications. (III, 2)

25. Although data on UDCA treatment during pregnancy and breastfeeding remains limited, continued use of UDCA can be considered in those patients after special counseling on these particular issues. (III, 2)

\section{Natural history and prognosis}

\section{Natural history and clinical course}

The natural history of PBC can be divided into four phases [221]: preclinical, asymptomatic, symptomatic, and terminal phase. In the pre-UDCA era, PBC patients were usually diagnosed at an advanced stage due to the absence of screening liver chemistries, limited availability of AMA tests and effective therapy, with a median survival of 6-10 years [222-225].

UDCA treatment has dramatically improvd the prognosis of PBC patients. The survival rate of the early-stage patients with complete response to UDCA therapy was similar to that of the general population [111, 115]. Liver transplant-free survival rate was significantly improved even in those with incomplete response to UDCA compared with no treatment [109]. In the UDCA era, the 5-year liver-related fatality and decompensation incidence in the Asia-Pacific region were $4.02 \%$ and $6.95 \%$, respectively [4], which were comparable to that in the Western countries. 


\section{Risk factors for poor clinical outcomes}

In addition to biochemical response to UDCA, several clinical, biochemical, and histological features also have prognostic significance for PBC patients. Cirrhosis at baseline and higher bilirubin are widely recongnized as strong predictors of worse long-term outcomes. Younger age at presentation [112, 226], alcohol consumption, smoking [96], and the onset of symptoms [227, 228] are also predictors of poorer prognosis. It is controversial whether male sex is associated with poorer long-term outcomes in PBC $[45,112,226]$. It is reported that anti-gp210 and anti-sp100 antibodies are associated with the advanced course and poorer prognosis [84, 229-232]. Additionally, histological features including fibrosis or cirrhosis, interface activity, ductopenia, and chronic cholestasis are critical facotors to predict biochemical response and clinical outcome in PBC patients [111, 112, 119, 233-235].

Finally, the impact of past HBV infection on the clinical outcomes of PBC is controversial. One study found that past $\mathrm{HBV}$ infection was a risk factor for $\mathrm{HCC}$ occurrence in PBC patients [67]. However, another large cohort recently reported from China demonstrated that past $\mathrm{HBV}$ infection (HBsAg negative and anti-HBc positive) did not compromise the prognosis of $\mathrm{PBC}$ patients [45].

Overall, baseline disease stage and biochemical response to UDCA are the two most important predictors for PBC patients' survival. Risk stratification based on clinical, biochemical, and histological features of PBC patients will facilitate the optimization of clinical management.

\section{Future research and horizons}

Identification of mitochondrial autoantigens have facilitated the earlier diagnosis and introduction of UDCA as first-line therapy significantly has altered the natural history of PBC. Nevertheless, many mysteries and unmet medical needs still exist in the understanding, diagnosis, and management of PBC.

Firstly, although PBC is considered an autoimmune liver disease, it remains unclear what environmental factors directly trigger the loss of self-tolerance to BECs, thereby leading to injury of intrahepatic ductules. While diagnostic utility of AMAs in PBC is remarkable, its pathogenic role remains to elucidate. Therefore, experimental studies with animal models recapitulating human PBC and relevant translational studies would generate new knowledge on the etiopathogenesis, thereby facilitating the discovery of novel therapeutic modalities.

Secondly, the clinical features and natural history of atypical clinical phenotype (such as preclinical or subclinical, AMA-negative disease, and vanishing bile duct) or variants of PBC (PBC with AIH features, PBC recurrence after liver transplantation) should be further investigated to optimize the management strategy for these subgroups.

Thirdly, although UDCA is the treatment of choice for $\mathrm{PBC}$, the therapeutic responses are not always predictable. Hence, it is necessary to investigate the clinical and laboratory stratification factors to provide individualized care with available therapeutic agents, including UDCA, OCA, fibrates, and budesonide.

Finally, collaborative efforts of scientists, clinicians, methodologists, and ethical experts are pivotal to accelerate the clinical development of novel therapies. The potential targets include the critical molecular pathways that may trigger the autoimmune reactivity against intrahepatic BECs or mediate disabling symptoms such as intractable fatigue and pruritus. Specifically, the merit of the early use of immunomodulatory therapy to change the natural history of PBC should be explored in the near future. Theoretically, immunological agents such as rituximab (anti-CD20 antibody) and ustekinumab (anti-IL-12/IL-23 antibody) are likely efficacious for patients with early-stage PBC, but not for patients at an advanced stage with UDCA-resistance. Obviously, the stringent ethical rules should be leveraged in the context of enormous unmet clinical needs to facilitate the design and conduct of clinical trials of novel therapies for PBC.

Acknowledgements The Asia-Pacific Guidelines committee would like to thank the authors and reviewers for contributing their expertise to the production of this Clinical Practice Guidance.

The authors thank the team member of Prof. Yuanyuan Kong (Na Zeng, Min Li, Qian Zhang and Zhiqiang Liu) for excellent methodologial support, and team members of Prof. Jidong Jia (Dr. Shuxiang Li, Dr. Tingting Lv, Dr. Qiuju Tian, Dr Shan Shan, Dr. Xinyan Zhao, Dr. Hong $\mathrm{Ma}$, and Dr. Xiaojuan $\mathrm{Ou}$ ) for literature review, manuscript drafting, microphotograph choosing and administrative support, special thanks to Prof. Ruqi Tang and Dr. Qiaoyan Liu (Renji Hospital, Shanghai Jiao Tong University) and Prof. Ping Wang (Beijing Friendship Hospital, Capital Medical University) for illustrating the figure of PBC pathogenesis.

Author contributions JJ, AT, HY, XM and CE designed, revised and finalized the manuscript. WD and SC searched the literature and drafted the manuscript. YK assessed and graded the quality of identified evidence, all the other authors critically reviewed and revised the recommendations. All authors read and approved the final manuscript.

Funding The group of this PBC guidance did not receive any financially support.

Availability of data and material Not applicable.

Code availability Not applicable.

\section{Declarations}

Conflict of interest This guidance were independently prepared and peer reviewed, and all contributors disclosed their conflicts of interest. Hong You, Xiong Ma, Cumali Efe, Guiqiang Wang, Sook-Hyang 
Jeong, Kazumichi Abe, Weijia Duan,Sha Chen, Yuanyuan Kong, Dong Zhang, Lai Wei, Fu-Sheng Wang, Han-Chieh Lin, Jin Mo Yang,Tawesak Tanwandee, Rino A. Gani, Diana A. Payawal, Barjesh C. Sharma, Jinlin Hou,Osamu Yokosuka, A. Kadir Dokmeci, Darrell Crawford, Jia-Horng Kao, Teerha Piratvisuth,Dong Jin Suh, Laurentius A. Lesmana, Jose Sollano, George Lau, Shiv K. Sarin, Masao Omata, Atsushi Tanaka, Jidong Jia these authors have nothing to disclose.

Ethics approval Not applicable.

Consent to participate Not applicable.

Consent for publication Written informed consent for publication was obtained from all participants.

Open Access This article is licensed under a Creative Commons Attribution 4.0 International License, which permits use, sharing, adaptation, distribution and reproduction in any medium or format, as long as you give appropriate credit to the original author(s) and the source, provide a link to the Creative Commons licence, and indicate if changes were made. The images or other third party material in this article are included in the article's Creative Commons licence, unless indicated otherwise in a credit line to the material. If material is not included in the article's Creative Commons licence and your intended use is not permitted by statutory regulation or exceeds the permitted use, you will need to obtain permission directly from the copyright holder. To view a copy of this licence, visit http://creativecommons.org/licenses/by/4.0/.

\section{References}

1. Guyatt GH, Oxman AD, Vist GE, et al. GRADE: an emerging consensus on rating quality of evidence and strength of recommendations. BMJ. 2008;336:924-926

2. Boonstra K, Beuers U, Ponsioen CY. Epidemiology of primary sclerosing cholangitis and primary biliary cirrhosis: a systematic review. J Hepatol. 2012;56:1181-1188

3. Lv T, Chen S, Li M, et al. Regional variation and temporal trend of primary biliary cholangitis epidemiology: A systematic review and meta-analysis. J Gastroenterol Hepatol. 2020;36:1423-1434

4. Zeng N, Duan W, Chen S, et al. Epidemiology and clinical course of primary biliary cholangitis in the Asia-Pacific region: a systematic review and meta-analysis. Hepatol Int. 2019;13:788-799

5. Ngu JH, Gearry RB, Wright AJ, et al. Low incidence and prevalence of primary biliary cirrhosis in Canterbury, New Zealand: a population-based study. Hepatol Int. 2012;6:796-800

6. Sood S, Gow PJ, Christie JM, et al. Epidemiology of primary biliary cirrhosis in Victoria, Australia: high prevalence in migrant populations. Gastroenterology. 2004;127:470-475

7. Sakugawa $H$, Nakasone $H$, Nakayoshi T, et al. Epidemiology of primary biliary cirrhosis among women with elevated gammaglutamyl transpeptidase levels in Okinawa Japan. Hepatol Res. 2003;26:330-336

8. Shibata M, Onozuka Y, Morizane T, et al. Prevalence of antimitochondrial antibody in Japanese corporate workers in Kanagawa prefecture. J Gastroenterol. 2004;39:255-259

9. Jiang XH, Zhong RQ, Fan XY, et al. Characterization of M2 antibodies in asymptomatic Chinese population. World J Gastroenterol. 2003;9:2128-2131

10. Liu H, Liu Y, Wang L, et al. Prevalence of primary biliary cirrhosis in adults referring hospital for annual health check-up in Southern China. BMC Gastroenterol. 2010;10:100
11. Kim KA, Ki M, Choi HY, et al. Population-based epidemiology of primary biliary cirrhosis in South Korea. Aliment Pharmacol Ther. 2016;43:154-162

12. Tanaka A, Mori M, Matsumoto K, et al. Increase trend in the prevalence and male-to-female ratio of primary biliary cholangitis, autoimmune hepatitis, and primary sclerosing cholangitis in Japan. Hepatol Res. 2019;49:881-889

13. Cheung KS, Seto WK, Fung J, et al. Epidemiology and natural history of primary biliary cholangitis in the Chinese: a territorybased study in Hong Kong between 2000 and 2015. Clin Transl Gastroenterol. 2017;8:e116

14. Amarapurkar DN, Patel ND. Spectrum of autoimmune liver diseases in western India. J Gastroenterol Hepatol. 2007;22:2112-2117

15. Lleo A, Leung PSC, Hirschfield GM, et al. The pathogenesis of primary biliary cholangitis: a comprehensive review. Semin Liver Dis. 2020;40:34-48

16. Gulamhusein AF, Hirschfield GM. Primary biliary cholangitis: pathogenesis and therapeutic opportunities. Nat Rev Gastroenterol Hepatol. 2020;17:93-110

17. Wijarnpreecha K, Werlang M, Panjawatanan P, et al. Association between smoking and risk of primary biliary cholangitis: a systematic review and meta-analysis. J Gastrointestin Liver Dis. 2019;28:197-203

18. Ala A, Stanca CM, Bu-Ghanim M, et al. Increased prevalence of primary biliary cirrhosis near Superfund toxic waste sites. Hepatology. 2006;43:525-531

19. Prince MI, Ducker SJ, James OF. Case-control studies of risk factors for primary biliary cirrhosis in two United Kingdom populations. Gut. 2010;59:508-512

20. Corpechot C, Chrétien Y, Chazouillères O, et al. Demographic, lifestyle, medical and familial factors associated with primary biliary cirrhosis. J Hepatol. 2010;53:162-169

21. Tang R, Wei Y, Li Y, et al. Gut microbial profile is altered in primary biliary cholangitis and partially restored after UDCA therapy. Gut. 2018;67:534-541

22. Gulamhusein AF, Juran BD, Lazaridis KN. Genome-wide association studies in primary biliary cirrhosis. Semin Liver Dis. 2015;35:392-401

23. Carbone M, Lleo A, Sandford RN, et al. Implications of genomewide association studies in novel therapeutics in primary biliary cirrhosis. Eur J Immunol. 2014;44:945-954

24. Wang C, Zheng X, Jiang P, et al. Genome-wide association studies of specific antinuclear autoantibody subphenotypes in primary biliary cholangitis. Hepatology. 2019;70:294-307

25. Hirschfield GM, Gershwin ME. The immunobiology and pathophysiology of primary biliary cirrhosis. Annu Rev Pathol. 2013;8:303-330

26. Hitomi Y, Ueno K, Kawai Y, et al. POGLUT1, the putative effector gene driven by rs2293370 in primary biliary cholangitis susceptibility locus chromosome 3q13.33. Sci Rep. 2019;9:102

27. Qiu F, Tang R, Zuo X, et al. A genome-wide association study identifies six novel risk loci for primary biliary cholangitis. Nat Commun. 2017;8:14828

28. Selmi C, Lleo A, Pasini S, et al. Innate immunity and primary biliary cirrhosis. Curr Mol Med. 2009;9:45-51

29. Kikuchi K, Lian ZX, Yang GX, et al. Bacterial CpG induces hyper-IgM production in CD27(+) memory B cells in primary biliary cirrhosis. Gastroenterology. 2005;128:304-312

30. Shimoda S, Harada K, Niiro H, et al. CX3CL1 (fractalkine): a signpost for biliary inflammation in primary biliary cirrhosis. Hepatology. 2010;51:567-575

31. Mao TK, Lian ZX, Selmi C, et al. Altered monocyte responses to defined TLR ligands in patients with primary biliary cirrhosis. Hepatology. 2005;42:802-808 
32. Trauner M, Halilbasic E. Nuclear receptors as new perspective for the management of liver diseases. Gastroenterology. 2011;140:1120-1125.e1-12

33. Tsuda M, Ambrosini YM, Zhang W, et al. Fine phenotypic and functional characterization of effector cluster of differentiation 8 positive $\mathrm{T}$ cells in human patients with primary biliary cirrhosis. Hepatology. 2011;54:1293-1302

34. Lan RY, Cheng C, Lian ZX, et al. Liver-targeted and peripheral blood alterations of regulatory $\mathrm{T}$ cells in primary biliary cirrhosis. Hepatology. 2006;43:729-737

35. Zhang $\mathrm{H}$, Lian $\mathrm{M}$, Zhang J, et al. A functional characteristic of cysteine-rich protein 61: Modulation of myeloid-derived suppressor cells in liver inflammation. Hepatology. 2018;67:232-246

36. Li SX, Lv TT, Zhang CP, et al. Alteration of liver-infiltrated and peripheral blood double-negative $\mathrm{T}$ cells in primary biliary cholangitis. Liver Int. 2019;39:1755-1767

37. Jiang X, Lian M, Li Y, et al. The immunobiology of mucosalassociated invariant $\mathrm{T}$ cell (MAIT) function in primary biliary cholangitis: Regulation by cholic acid-induced Interleukin-7. J Autoimmun. 2018;90:64-75

38. Kyriakou DS, Alexandrakis MG, Zachou K, et al. Hemopoietic progenitor cells and bone marrow stromal cells in patients with autoimmune hepatitis type 1 and primary biliary cirrhosis. J Hepatol. 2003;39:679-685

39. Zachou K, Rigopoulou EI, Tsikrikoni A, et al. Autoimmune hepatitis type 1 and primary biliary cirrhosis have distinct bone marrow cytokine production. J Autoimmun. 2005;25:283-288

40. Tsikrikoni A, Kyriakou DS, Rigopoulou EI, et al. Markers of cell activation and apoptosis in bone marrow mononuclear cells of patients with autoimmune hepatitis type 1 and primary biliary cirrhosis. J Hepatol. 2005;42:393-399

41. Selmi C, Bowlus CL, Gershwin ME, et al. Primary biliary cirrhosis. Lancet. 2011;377:1600-1609

42. Lindor KD, Bowlus CL, Boyer J, et al. Primary biliary cholangitis: 2018 practice guidance from the American Association for the Study of Liver Diseases. Hepatology. 2019;69:394-419

43. EASL Clinical Practice Guidelines. The diagnosis and management of patients with primary biliary cholangitis. J Hepatol. 2017;67:145-172

44. Hirschfield GM, Dyson JK, Alexander GJM, et al. The British Society of Gastroenterology/UK-PBC primary biliary cholangitis treatment and management guidelines. Gut. 2018;67:1568-1594

45. Chen S, Duan W, Li M, et al. Prognosis of 732 ursodeoxycholic acid-treated patients with primary biliary cholangitis: a single center follow-up study from China. J Gastroenterol Hepatol. 2018;34:1236-1241

46. Lin CY, Cheng YT, Chang ML, et al. The extrahepatic events of Asian patients with primary biliary cholangitis: a 30-year cohort study. Sci Rep. 2019;9:7577

47. Murillo PCF, Goet JC, Lammers WJ, et al. Milder disease stage in patients with primary biliary cholangitis over a 44-year period: a changing natural history. Hepatology. 2018;67:1920-1930

48. Kubota J, Ikeda F, Terada R, et al. Mortality rate of patients with asymptomatic primary biliary cirrhosis diagnosed at age 55 years or older is similar to that of the general population. $\mathrm{J}$ Gastroenterol. 2009;44:1000-1006

49. Prince MI, Chetwynd A, Craig WL, et al. Asymptomatic primary biliary cirrhosis: clinical features, prognosis, and symptom progression in a large population based cohort. Gut. 2004;53:865-870

50. Carey EJ, Ali AH, Lindor KD. Primary biliary cirrhosis. Lancet. 2015;386:1565-1575

51. Carbone M, Bufton S, Monaco A, et al. The effect of liver transplantation on fatigue in patients with primary biliary cirrhosis: a prospective study. J Hepatol. 2013;59:490-494
52. Fisk JD, Ritvo PG, Ross L, et al. Measuring the functional impact of fatigue: initial validation of the fatigue impact scale. Clin Infect Dis. 1994;18(Suppl 1):S79-83

53. Jacoby A, Rannard A, Buck D, et al. Development, validation, and evaluation of the PBC-40, a disease specific health related quality of life measure for primary biliary cirrhosis. Gut. 2005;54:1622-1629

54. Abbas G, Jorgensen RA, Lindor KD. Fatigue in primary biliary cirrhosis. Nat Rev Gastroenterol Hepatol. 2010;7:313-319

55. Lindor KD, Gershwin ME, Poupon R, et al. Primary biliary cirrhosis. Hepatology. 2009;50:291-308

56. Yagi M, Tanaka A, Abe M, et al. Symptoms and health-related quality of life in Japanese patients with primary biliary cholangitis. Sci Rep. 2018;8:12542

57. Hegade VS, Bolier R, Oude ERP, et al. A systematic approach to the management of cholestatic pruritus in primary biliary cirrhosis. Front Gastroenterol. 2016;7:158-166

58. Chalifoux SL, Konyn PG, Choi G, et al. Extrahepatic manifestations of primary biliary cholangitis. Gut Liver. 2017;11:771-780

59. Floreani A, Franceschet I, Cazzagon N, et al. Extrahepatic autoimmune conditions associated with primary biliary cirrhosis. Clin Rev Allergy Immunol. 2015;48:192-197

60. Efe C, Torgutalp M, Henriksson I, et al. Extrahepatic autoimmune diseases in primary biliary cholangitis: prevalence and significance for clinical presentation and disease outcome. J Gastroenterol Hepatol. 2021;36:936-942

61. Granito A, Muratori P, Muratori L, et al. Antibodies to SS-A/ Ro-52kD and centromere in autoimmune liver disease: a clue to diagnosis and prognosis of primary biliary cirrhosis. Aliment Pharmacol Ther. 2007;26:831-838

62. Parveen S, Morshed SA, Nishioka M. High prevalence of antibodies to recombinant CENP-B in primary biliary cirrhosis: nuclear immunofluorescence patterns and ELISA reactivities. J Gastroenterol Hepatol. 1995;10:438-445

63. Allocca M, Crosignani A, Gritti A, et al. Hypercholesterolaemia is not associated with early atherosclerotic lesions in primary biliary cirrhosis. Gut. 2006;55:1795-1800

64. Fan J, Wang Q, Sun L. Association between primary biliary cholangitis and osteoporosis: meta-analysis. Clin Rheumatol. 2017;36:2565-2571

65. Levy C, Lindor KD. Management of osteoporosis, fat-soluble vitamin deficiencies, and hyperlipidemia in primary biliary cirrhosis. Clin Liver Dis. 2003;7:901-910

66. Colina F, Pinedo F, Solís JA, et al. Nodular regenerative hyperplasia of the liver in early histological stages of primary biliary cirrhosis. Gastroenterology. 1992;102:1319-1324

67. Rong G, Wang H, Bowlus CL, et al. Incidence and risk factors for hepatocellular carcinoma in primary biliary cirrhosis. Clin Rev Allergy Immunol. 2015;48:132-141

68. Harada K, Hirohara J, Ueno Y, et al. Incidence of and risk factors for hepatocellular carcinoma in primary biliary cirrhosis: national data from Japan. Hepatology. 2013;57:1942-1949

69. Rigopoulou EI, Dalekos GN. Current Trends and Characteristics of Hepatocellular Carcinoma in Patients with Autoimmune Liver Diseases. Cancers (Basel). 2021;13:1023

70. Granito A, Muratori P, Quarneti C, et al. Antinuclear antibodies as ancillary markers in primary biliary cirrhosis. Expert Rev Mol Diagn. 2012;12:65-74

71. Gatselis NK, Dalekos GN. Molecular diagnostic testing for primary biliary cholangitis. Expert Rev Mol Diagn. 2016;16:1001-1010

72. Vergani D. Towards the serological diagnosis of primary biliary cirrhosis. Liver Int. 2015;35:299-301

73. Dalekos GN, Gatselis NK. Variant and specific forms of autoimmune cholestatic liver diseases. Arch Immunol Ther Exp (Warsz). 2019;67:197-211 
74. Gabeta S, Norman GL, Liaskos C, et al. Diagnostic relevance and clinical significance of the new enhanced performance M2 (MIT3) ELISA for the detection of IgA and IgG antimitochondrial antibodies in primary biliary cirrhosis. J Clin Immunol. 2007;27:378-87.

75. Liu H, Norman GL, Shums Z, et al. PBC screen: an IgG/IgA dual isotype ELISA detecting multiple mitochondrial and nuclear autoantibodies specific for primary biliary cirrhosis. J Autoimmun. 2010;35:436-42.

76. Muratori L, Muratori P, Granito A, et al. The Western immunoblotting pattern of anti-mitochondrial antibodies is independent of the clinical expression of primary biliary cirrhosis. Dig Liver Dis. 2005;37:108-112

77. Leung PS, Rossaro L, Davis PA, et al. Antimitochondrial antibodies in acute liver failure: implications for primary biliary cirrhosis. Hepatology. 2007;46:1436-1442

78. Zhang Q, Liu Z, Wu S, et al. Meta-analysis of antinuclear antibodies in the diagnosis of antimitochondrial antibodynegative primary biliary cholangitis. Gastroenterol Res Pract. 2019;2019:8959103

79. Granito A, Muratori P, Muratori L, et al. Antinuclear antibodies giving the "multiple nuclear dots" or the "rim-like/membranous" patterns: diagnostic accuracy for primary biliary cirrhosis. Aliment Pharmacol Ther. 2006;24:1575-1583

80. Norman GL, Yang CY, Ostendorff HP, et al. Anti-kelch-like 12 and anti-hexokinase 1: novel autoantibodies in primary biliary cirrhosis. Liver Int. 2015;35:642-651

81. Janka C, Selmi C, Gershwin ME, et al. Small ubiquitin-related modifiers: a novel and independent class of autoantigens in primary biliary cirrhosis. Hepatology. 2005;41:609-616

82. Granito A, Yang WH, Muratori L, et al. PML nuclear body component Sp140 is a novel autoantigen in primary biliary cirrhosis. Am J Gastroenterol. 2010;105:125-131

83. Ali AH, Carey EJ, Lindor KD. Diagnosis and management of primary biliary cirrhosis. Expert Rev Clin Immunol. 2014;10:1667-1678

84. Nakamura M, Kondo H, Mori T, et al. Anti-gp210 and anti-centromere antibodies are different risk factors for the progression of primary biliary cirrhosis. Hepatology. 2007;45:118-127

85. Haliloglu N, Erden A, Erden I. Primary biliary cirrhosis: evaluation with T2-weighted MR imaging and MR cholangiopancreatography. Eur J Radiol. 2009;69:523-527

86. Corpechot C, Carrat F, Poujol-Robert A, et al. Noninvasive elastography-based assessment of liver fibrosis progression and prognosis in primary biliary cirrhosis. Hepatology. 2012;56:198-208

87. Friedrich-Rust M, Müller C, Winckler A, et al. Assessment of liver fibrosis and steatosis in PBC with FibroScan, MRI, MR-spectroscopy, and serum markers. J Clin Gastroenterol. 2010;44:58-65

88. Ludwig J, Dickson ER, McDonald GS. Staging of chronic nonsuppurative destructive cholangitis (syndrome of primary biliary cirrhosis). Virchows Arch A Pathol Anat Histol. 1978;379:103-112

89. Scheuer PJ. Primary biliary cirrhosis: diagnosis, pathology and pathogenesis. Postgrad Med J. 1983;59(Suppl 4):106-115

90. Degott C, Zafrani ES, Callard P, et al. Histopathological study of primary biliary cirrhosis and the effect of ursodeoxycholic acid treatment on histology progression. Hepatology. 1999;29:1007-1012

91. Corpechot C, Carrat F, Poupon R, et al. Primary biliary cirrhosis: incidence and predictive factors of cirrhosis development in ursodiol-treated patients. Gastroenterology. 2002;122:652-658

92. Nakanuma Y, Zen Y, Harada K, et al. Application of a new histological staging and grading system for primary biliary cirrhosis to liver biopsy specimens: Interobserver agreement. Pathol Int. 2010;60:167-174
93. Harada K, Hsu M, Ikeda H, et al. Application and validation of a new histologic staging and grading system for primary biliary cirrhosis. J Clin Gastroenterol. 2013;47:174-181

94. Kakuda Y, Harada K, Sawada-Kitamura S, et al. Evaluation of a new histologic staging and grading system for primary biliary cirrhosis in comparison with classical systems. Hum Pathol. 2013;44:1107-1117

95. Papamichalis PA, Zachou K, Papamichali RA, et al. Promyelocytic leukemia antigen expression: a histological marker for primary biliary cholangitis diagnosis. J Transl Int Med. 2021;9:43-51

96. Corpechot C, Gaouar F, Chrétien Y, et al. Smoking as an independent risk factor of liver fibrosis in primary biliary cirrhosis. J Hepatol. 2012;56:218-224

97. Híndi M, Levy C, Couto CA, et al. Primary biliary cirrhosis is more severe in overweight patients. J Clin Gastroenterol. 2013;47:e28-32

98. Minuk GY, Iliant V, Zhou N, et al. Concomitant nonalcoholic fatty liver disease does not alter the activity, severity or course of primary biliary cholangitis. Liver Int. 2018;38:1110-1116

99. Consensus on the diagnosis and management of primary biliary cirrhosis (cholangitis). Zhonghua Gan Zang Bing Za Zhi 2016;24:5-13.

100. Guidelines for the management of primary biliary cirrhosis: The Intractable Hepatobiliary Disease Study Group supported by the Ministry of Health, Labour and Welfare of Japan. Hepatol Res 2014;44 (Suppl S1):71-90.

101. Angulo P, Dickson ER, Therneau TM, et al. Comparison of three doses of ursodeoxycholic acid in the treatment of primary biliary cirrhosis: a randomized trial. J Hepatol. 1999;30:830-835

102. Ma H, Zeng M, Han Y, et al. A multicenter, randomized, doubleblind trial comparing the efficacy and safety of TUDCA and UDCA in Chinese patients with primary biliary cholangitis. Medicine (Baltimore). 2016;95:e5391

103. Rudic JS, Poropat G, Krstic MN, et al. Ursodeoxycholic acid for primary biliary cirrhosis. Cochrane Database Syst Rev. 2012;12:CD000551

104. Gong Y, Huang Z, Christensen E, et al. Ursodeoxycholic acid for patients with primary biliary cirrhosis: an updated systematic review and meta-analysis of randomized clinical trials using Bayesian approach as sensitivity analyses. Am J Gastroenterol. 2007;102:1799-1807

105. Shi J, Wu C, Lin Y, et al. Long-term effects of mid-dose ursodeoxycholic acid in primary biliary cirrhosis: a metaanalysis of randomized controlled trials. Am J Gastroenterol. 2006;101:1529-1538

106. Poupon RE, Lindor KD, Parés A, et al. Combined analysis of the effect of treatment with ursodeoxycholic acid on histologic progression in primary biliary cirrhosis. J Hepatol. 2003;39:12-16

107. Angulo P, Batts KP, Therneau TM, et al. Long-term ursodeoxycholic acid delays histological progression in primary biliary cirrhosis. Hepatology. 1999;29:644-647

108. Corpechot C, Carrat F, Bahr A, et al. The effect of ursodeoxycholic acid therapy on the natural course of primary biliary cirrhosis. Gastroenterology. 2005;128:297-303

109. Harms $M H$, van Buuren $H R$, Corpechot $C$, et al. Ursodeoxycholic acid therapy and liver transplant-free survival in patients with primary biliary cholangitis. J Hepatol. 2019;71:357-365

110. Leoni MC, Amelung L, Lieveld FI, et al. Adherence to ursodeoxycholic acid therapy in patients with cholestatic and autoimmune liver disease. Clin Res Hepatol Gastroenterol. 2019;43:37-44

111. Corpechot $\mathrm{C}$, Abenavoli L, Rabahi N, et al. Biochemical response to ursodeoxycholic acid and long-term prognosis in primary biliary cirrhosis. Hepatology. 2008;48:871-877

112. Carbone M, Mells GF, Pells G, et al. Sex and age are determinants of the clinical phenotype of primary biliary 
cirrhosis and response to ursodeoxycholic acid. Gastroenterology. 2013;144:560-569.e7 (quiz e13-14)

113. Gatselis NK, Goet JC, Zachou K, et al. Factors associated with progression and outcomes of early stage primary biliary cholangitis. Clin Gastroenterol Hepatol. 2020;18:684-692.e6

114. Zhang LN, Shi TY, Shi XH, et al. Early biochemical response to ursodeoxycholic acid and long-term prognosis of primary biliary cirrhosis: results of a 14-year cohort study. Hepatology. 2013;58:264-272

115. Parés A, Caballería L, Rodés J. Excellent long-term survival in patients with primary biliary cirrhosis and biochemical response to ursodeoxycholic Acid. Gastroenterology. 2006;130:715-720

116. Angulo P, Lindor KD, Therneau TM, et al. Utilization of the Mayo risk score in patients with primary biliary cirrhosis receiving ursodeoxycholic acid. Liver. 1999;19:115-121

117. Kuiper EM, Hansen BE, de Vries RA, et al. Improved prognosis of patients with primary biliary cirrhosis that have a biochemical response to ursodeoxycholic acid. Gastroenterology. 2009;136:1281-1287

118. Azemoto N, Abe M, Murata Y, et al. Early biochemical response to ursodeoxycholic acid predicts symptom development in patients with asymptomatic primary biliary cirrhosis. J Gastroenterol. 2009;44:630-634

119. Kumagi T, Guindi M, Fischer SE, et al. Baseline ductopenia and treatment response predict long-term histological progression in primary biliary cirrhosis. Am J Gastroenterol. 2010;105:2186-2194

120. Momah N, Silveira MG, Jorgensen R, et al. Optimizing biochemical markers as endpoints for clinical trials in primary biliary cirrhosis. Liver Int. 2012;32:790-795

121. Corpechot $\mathrm{C}$, Chazouillères $\mathrm{O}$, Poupon $\mathrm{R}$. Early primary biliary cirrhosis: biochemical response to treatment and prediction of long-term outcome. J Hepatol. 2011;55:1361-1367

122. Chen S, Duan W, You H, et al. A brief review on prognostic models of primary biliary cholangitis. Hepatol Int. 2017;11:412-418

123. Lammers WJ, Hirschfield GM, Corpechot C, et al. Development and validation of a scoring system to predict outcomes of patients with primary biliary cirrhosis receiving ursodeoxycholic acid therapy. Gastroenterology. 2015;149:1804-1812.e4

124. Carbone M, Sharp SJ, Flack S, et al. The UK-PBC risk scores: derivation and validation of a scoring system for long-term prediction of end-stage liver disease in primary biliary cholangitis. Hepatology. 2016;63:930-950

125. Efe C, Taşçilar K, Henriksson I, et al. Validation of risk scoring systems in ursodeoxycholic acid-treated patients with primary biliary cholangitis. Am J Gastroenterol. 2019;114:1101-1108

126. Lammers WJ, van Buuren HR, Hirschfield GM, et al. Levels of alkaline phosphatase and bilirubin are surrogate end points of outcomes of patients with primary biliary cirrhosis: an international follow-up study. Gastroenterology. 2014;147:1338-1349. e5 (quiz e15)

127. Murillo PCF, Harms MH, Lindor KD, et al. Goals of treatment for improved survival in primary biliary cholangitis: treatment target should be bilirubin within the normal range and normalization of alkaline phosphatase. Am J Gastroenterol. 2020;115:1066-1074

128. Carbone M, Nardi A, Flack S, et al. Pretreatment prediction of response to ursodeoxycholic acid in primary biliary cholangitis: development and validation of the UDCA Response Score. Lancet Gastroenterol Hepatol. 2018;3:626-634

129. Yagi M, Matsumoto K, Komori A, et al. A validation study of the Ursodeoxycholic Acid Response Score in Japanese patients with primary biliary cholangitis. Liver Int. 2020;40:1926-1933

130. Hirschfield GM, Mason A, Luketic V, et al. Efficacy of obeticholic acid in patients with primary biliary cirrhosis and inadequate response to ursodeoxycholic acid. Gastroenterology. 2015;148:751-761.e8

131. Kowdley KV, Luketic V, Chapman R, et al. A randomized trial of obeticholic acid monotherapy in patients with primary biliary cholangitis. Hepatology. 2018;67:1890-1902

132. Nevens F, Andreone P, Mazzella G, et al. A Placebo-controlled trial of obeticholic acid in primary biliary cholangitis. N Engl J Med. 2016;375:631-643

133. Trauner M, Nevens F, Shiffman ML, et al. Long-term efficacy and safety of obeticholic acid for patients with primary biliary cholangitis: 3-year results of an international open-label extension study. Lancet Gastroenterol Hepatol. 2019;4:445-453

134. Han XF, Wang QX, Liu Y, et al. Efficacy of fenofibrate in Chinese patients with primary biliary cirrhosis partially responding to ursodeoxycholic acid therapy. J Dig Dis. 2012;13:219-224

135. Ohira H, Sato Y, Ueno T, et al. Fenofibrate treatment in patients with primary biliary cirrhosis. Am J Gastroenterol. 2002;97:2147-2149

136. Zhang Y, Li S, He L, et al. Combination therapy of fenofibrate and ursodeoxycholic acid in patients with primary biliary cirrhosis who respond incompletely to UDCA monotherapy: a metaanalysis. Drug Des Devel Ther. 2015;9:2757-2766

137. Duan W, Ou X, Wang X, et al. Efficacy and safety of fenofibrate add-on therapy for patients with primary biliary cholangitis and a suboptimal response to UDCA. Rev Esp Enferm Dig. 2018;110:557-563

138. Yin Q, Li J, Xia Y, et al. Systematic review and meta-analysis: bezafibrate in patients with primary biliary cirrhosis. Drug Des Devel Ther. 2015;9:5407-19.

139. Reig A, Sesé P, Parés A. Effects of bezafibrate on outcome and pruritus in primary biliary cholangitis with suboptimal ursodeoxycholic acid response. Am J Gastroenterol. 2018;113:49-55

140. Corpechot $\mathrm{C}$, Chazouillères O, Rousseau A, et al. A placebocontrolled trial of bezafibrate in primary biliary cholangitis. $\mathrm{N}$ Engl J Med. 2018;378:2171-2181

141. Honda A, Tanaka A, Kaneko T, et al. Bezafibrate improves GLOBE and UK-PBC scores and long-term outcomes in patients with primary biliary cholangitis. Hepatology. 2019;70:2035-2046

142. de Vries E, Bolier R, Goet J, et al. Fibrates for Itch (FITCH) in fibrosing cholangiopathies: a double-blind, randomized placebocontrolled Trial. Gastroenterology. 2021;160:734-743.e6

143. Bolier R, de Vries ES, Parés A, et al. Fibrates for the treatment of cholestatic itch (FITCH): study protocol for a randomized controlled trial. Trials. 2017;18:230

144. Rautiainen H, Kärkkäinen P, Karvonen AL, et al. Budesonide combined with UDCA to improve liver histology in primary biliary cirrhosis: a three-year randomized trial. Hepatology. 2005;41:747-752

145. Leuschner M, Maier KP, Schlichting J, et al. Oral budesonide and ursodeoxycholic acid for treatment of primary biliary cirrhosis: results of a prospective double-blind trial. Gastroenterology. 1999;117:918-925

146. Hirschfield GM, Beuers U, Kupcinskas L, et al. A placebocontrolled randomised trial of budesonide for PBC following an insufficient response to UDCA. J Hepatol. 2021;74:321-329

147. Hempfling W, Grunhage F, Dilger K, et al. Pharmacokinetics and pharmacodynamic action of budesonide in early- and late-stage primary biliary cirrhosis. Hepatology. 2003;38:196-202

148. Beuers U, Kremer AE, Bolier R, et al. Pruritus in cholestasis: facts and fiction. Hepatology. 2014;60:399-407

149. Yu H, Zhao T, Liu S, et al. MRGPRX4 is a bile acid receptor for human cholestatic itch. Elife. 2019;8:48431

150. Datta DV, Sherlock S. Cholestyramine for long term relief of the pruritus complicating intrahepatic cholestasis. Gastroenterology. 1966;50:323-332 
151. Tandon $\mathrm{P}$, Rowe BH, Vandermeer B, et al. The efficacy and safety of bile acid binding agents, opioid antagonists, or rifampin in the treatment of cholestasis-associated pruritus. Am J Gastroenterol. 2007;102:1528-1536

152. Khurana S, Singh P. Rifampin is safe for treatment of pruritus due to chronic cholestasis: a meta-analysis of prospective randomized-controlled trials. Liver Int. 2006;26:943-948

153. Bachs L, Parés A, Elena M, et al. Comparison of rifampicin with phenobarbitone for treatment of pruritus in biliary cirrhosis. Lancet. 1989;1:574-576

154. Prince MI, Burt AD, Jones DE. Hepatitis and liver dysfunction with rifampicin therapy for pruritus in primary biliary cirrhosis. Gut. 2002;50:436-439

155. Markowitz JS, DeVane CL. Rifampin-induced selective serotonin reuptake inhibitor withdrawal syndrome in a patient treated with sertraline. J Clin Psychopharmacol. 2000;20:109-110

156. Yagi $M$, Tanaka $A$, Namisaki $T$, et al. Is patient-reported outcome improved by nalfurafine hydrochloride in patients with primary biliary cholangitis and refractory pruritus? A post-marketing, single-arm, prospective study. J Gastroenterol. 2018;53:1151-1158

157. Hegade VS, Kendrick SF, Dobbins RL, et al. Effect of ileal bile acid transporter inhibitor GSK2330672 on pruritus in primary biliary cholangitis: a double-blind, randomised, placebo-controlled, crossover, phase 2a study. Lancet. 2017;389:1114-1123

158. Buster EH, Flink HJ, Cakaloglu Y, et al. Sustained HBeAg and $\mathrm{HBsAg}$ loss after long-term follow-up of $\mathrm{HBeAg}$-positive patients treated with peginterferon alpha-2b. Gastroenterology. 2008;135:459-467

159. EASL Clinical Practice Guidelines on nutrition in chronic liver disease. J Hepatol 2019;70:172-193.

160. Guo GY, Shi YQ, Wang L, et al. Serum vitamin D level is associated with disease severity and response to ursodeoxycholic acid in primary biliary cirrhosis. Aliment Pharmacol Ther. 2015;42:221-230

161. Agmon-Levin N, Kopilov R, Selmi C, et al. Vitamin D in primary biliary cirrhosis, a plausible marker of advanced disease. Immunol Res. 2015;61:141-146

162. Wang Z, Peng C, Wang P, et al. Serum vitamin D level is related to disease progression in primary biliary cholangitis. Scand $\mathbf{J}$ Gastroenterol. 2020;55:1333-1340

163. Guañabens N, Cerdá D, Monegal A, et al. Low bone mass and severity of cholestasis affect fracture risk in patients with primary biliary cirrhosis. Gastroenterology. 2010;138:2348-2356

164. Rudic JS, Giljaca V, Krstic MN, et al. Bisphosphonates for osteoporosis in primary biliary cirrhosis. Cochrane Database Syst Rev 2011;CD009144.

165. Guañabens N, Monegal A, Cerdá D, et al. Randomized trial comparing monthly ibandronate and weekly alendronate for osteoporosis in patients with primary biliary cirrhosis. Hepatology. 2013;58:2070-2078

166. Rudic JS, Poropat G, Krstic MN et al. Hormone replacement for osteoporosis in women with primary biliary cirrhosis. Cochrane Database Syst Rev 2011;CD009146.

167. Arase Y, Tsuruya K, Hirose S, et al. Efficacy and safety of 3-year denosumab therapy for osteoporosis in patients with autoimmune liver diseases. Hepatology. 2019;71:757-759

168. Jones DE, Newton JL. An open study of modafinil for the treatment of daytime somnolence and fatigue in primary biliary cirrhosis. Aliment Pharmacol Ther. 2007;25:471-476

169. Lammers WJ, Kowdley KV, van Buuren HR. Predicting outcome in primary biliary cirrhosis. Ann Hepatol. 2014;13:316-326

170. Moctezuma-Velazquez C, Saffioti F, Tasayco-Huaman S, et al. Non-invasive prediction of high-risk varices in patients with primary biliary cholangitis and primary sclerosing cholangitis. Am J Gastroenterol. 2019;114:446-452
171. Cavazza A, Caballería L, Floreani A, et al. Incidence, risk factors, and survival of hepatocellular carcinoma in primary biliary cirrhosis: comparative analysis from two centers. Hepatology. 2009;50:1162-1168

172. Trivedi PJ, Lammers WJ, van Buuren HR, et al. Stratification of hepatocellular carcinoma risk in primary biliary cirrhosis: a multicentre international study. Gut. 2016;65:321-329

173. Harada K, Nakanuma Y. Prevalence and risk factors of hepatocellular carcinoma in Japanese patients with primary biliary cirrhosis. Hepatol Res. 2014;44:133-140

174. Natarajan Y, Tansel A, Patel P, et al. Incidence of hepatocellular carcinoma in primary biliary cholangitis: a systematic review and meta-analysis. Dig Dis Sci. 2020;66:2439-2451

175. Aguilar MT, Carey EJ. Current status of liver transplantation for primary biliary cholangitis. Clin Liver Dis. 2018;22:613-624

176. Martin P, DiMartini A, Feng S, et al. Evaluation for liver transplantation in adults: 2013 practice guideline by the American Association for the Study of Liver Diseases and the American Society of Transplantation. Hepatology. 2014;59:1144-1165

177. Adam R, Karam V, Delvart V, et al. Evolution of indications and results of liver transplantation in Europe. A report from the European Liver Transplant Registry (ELTR). J Hepatol. 2012;57:675-688

178. Carbone M, Neuberger JM. Autoimmune liver disease, autoimmunity and liver transplantation. J Hepatol. 2014;60:210-223

179. Singal AK, Guturu P, Hmoud B, et al. Evolving frequency and outcomes of liver transplantation based on etiology of liver disease. Transplantation. 2013;95:755-760

180. Montano-Loza AJ, Hansen BE, Corpechot C, et al. Factors associated with recurrence of primary biliary cholangitis after liver transplantation and effects on graft and patient survival. Gastroenterology. 2019;156:96-107.e1

181. Khettry U, Anand N, Faul PN, et al. Liver transplantation for primary biliary cirrhosis: a long-term pathologic study. Liver Transpl. 2003;9:87-96

182. Silveira MG, Talwalkar JA, Lindor KD, et al. Recurrent primary biliary cirrhosis after liver transplantation. Am J Transplant. 2010;10:720-726

183. Bosch A, Dumortier J, Maucort-Boulch D, et al. Preventive administration of UDCA after liver transplantation for primary biliary cirrhosis is associated with a lower risk of disease recurrence. J Hepatol. 2015;63:1449-1458

184. Boberg KM, Chapman RW, Hirschfield GM, et al. Overlap syndromes: the International Autoimmune Hepatitis Group (IAIHG) position statement on a controversial issue. J Hepatol. 2011;54:374-385

185. Chinese consensus on the diagnosis and management of autoimmune hepatitis (2015). J Dig Dis 2017;18:247-264.

186. Dyson JK, De Martin E, Dalekos GN, et al. Review article: unanswered clinical and research questions in autoimmune hepatitisconclusions of the International Autoimmune Hepatitis Group Research Workshop. Aliment Pharmacol Ther. 2019;49:528-536

187. Chazouillères $\mathrm{O}$, Wendum $\mathrm{D}$, Serfaty L, et al. Primary biliary cirrhosis-autoimmune hepatitis overlap syndrome: clinical features and response to therapy. Hepatology. 1998;28:296-301

188. Yang F, Wang Q, Bian Z, et al. Autoimmune hepatitis: east meets west. J Gastroenterol Hepatol. 2015;30:1230-1236

189. Terziroli BB, Mieli-Vergani G, Vergani D, et al. The challenges of primary biliary cholangitis: What is new and what needs to be done. J Autoimmun. 2019;105:

190. Wang Q, Selmi C, Zhou X, et al. Epigenetic considerations and the clinical reevaluation of the overlap syndrome between primary biliary cirrhosis and autoimmune hepatitis. J Autoimmun. 2013;41:140-145 
191. Muratori P, Granito A, Pappas G, et al. The serological profile of the autoimmune hepatitis/primary biliary cirrhosis overlap syndrome. Am J Gastroenterol. 2009;104:1420-1425

192. Efe C, Purnak T, Ozaslan E, et al. The serological profile of the autoimmune hepatitis/primary biliary cirrhosis overlap syndrome. Am J Gastroenterol. 2010;105:226 (author reply 226-227)

193. Kuiper EM, Zondervan PE, van Buuren HR. Paris criteria are effective in diagnosis of primary biliary cirrhosis and autoimmune hepatitis overlap syndrome. Clin Gastroenterol Hepatol. 2010;8:530-534

194. Hennes EM, Zeniya M, Czaja AJ, et al. Simplified criteria for the diagnosis of autoimmune hepatitis. Hepatology. 2008;48:169-176

195. Alvarez F, Berg PA, Bianchi FB, et al. International Autoimmune Hepatitis Group Report: review of criteria for diagnosis of autoimmune hepatitis. J Hepatol. 1999;31:929-938

196. Yang F, Wang Q, Wang Z, et al. The natural history and prognosis of primary biliary cirrhosis with clinical features of autoimmune hepatitis. Clin Rev Allergy Immunol. 2016;50:114-123

197. Tanaka A, Harada K, Ebinuma H, et al. Primary biliary cirrhosis-autoimmune hepatitis overlap syndrome: a rationale for corticosteroids use based on a nation-wide retrospective study in Japan. Hepatol Res. 2011;41:877-886

198. Zhang H, Li S, Yang J, et al. A meta-analysis of ursodeoxycholic acid therapy versus combination therapy with corticosteroids for PBC-AIH-overlap syndrome: evidence from 97 monotherapy and 117 combinations. Prz Gastroenterol. 2015;10:148-155

199. Ozaslan E, Efe C, Heurgué-Berlot A, et al. Factors associated with response to therapy and outcome of patients with primary biliary cirrhosis with features of autoimmune hepatitis. Clin Gastroenterol Hepatol. 2014;12:863-869

200. Hirschfield GM, Heathcote EJ. Antimitochondrial antibody-negative primary biliary cirrhosis. Clin Liver Dis. 2008;12:323-331 (viii-ix)

201. Invernizzi $\mathrm{P}$, Crosignani $\mathrm{A}$, Battezzati $\mathrm{PM}$, et al. Comparison of the clinical features and clinical course of antimitochondrial antibody-positive and -negative primary biliary cirrhosis. Hepatology. 1997;25:1090-1095

202. Jin Q, Moritoki Y, Lleo A, et al. Comparative analysis of portal cell infiltrates in antimitochondrial autoantibody-positive versus antimitochondrial autoantibody-negative primary biliary cirrhosis. Hepatology. 2012;55:1495-1506

203. Juliusson G, Imam M, Björnsson ES, et al. Long-term outcomes in antimitochondrial antibody negative primary biliary cirrhosis. Scand J Gastroenterol. 2016;51:745-752

204. Metcalf JV, Mitchison HC, Palmer JM, et al. Natural history of early primary biliary cirrhosis. Lancet. 1996;348:1399-1402

205. Dahlqvist G, Gaouar F, Carrat F, et al. Large-scale characterization study of patients with antimitochondrial antibodies but nonestablished primary biliary cholangitis. Hepatology. 2017;65:152-163

206. Gulamhusein AF, Juran BD, Atkinson EJ, et al. Low incidence of primary biliary cirrhosis (PBC) in the first-degree relatives of $\mathrm{PBC}$ probands after 8 years of follow-up. Liver Int. 2016;36:1378-1382

207. Mattalia A, Quaranta S, Leung PS, et al. Characterization of antimitochondrial antibodies in health adults. Hepatology. 1998;27:656-661

208. Ohba K, Omagari K, Kinoshita H, et al. Primary biliary cirrhosis among atomic bomb survivors in Nagasaki Japan. J Clin Epidemiol. 2001;54:845-850

209. Chen BH, Wang QQ, Zhang W, et al. Screening of anti-mitochondrial antibody subtype M2 in residents at least 18 years of age in an urban district of Shanghai China. Eur Rev Med Pharmacol Sci. 2016;20:2052-2060
210. Sun C, Xiao X, Yan L, et al. Histologically proven AMA positive primary biliary cholangitis but normal serum alkaline phosphatase: Is alkaline phosphatase truly a surrogate marker. J Autoimmun. 2019;99:33-38

211. Terziroli BB, Stirnimann G, Mertens J, et al. Primary biliary cholangitis with normal alkaline phosphatase: a neglected clinical entity challenging current guidelines. J Autoimmun. 2021;116:102578

212. Poupon R, Chrétien Y, Chazouillères O, et al. Pregnancy in women with ursodeoxycholic acid-treated primary biliary cirrhosis. J Hepatol. 2005;42:418-419

213. Efe C, Kahramanoğlu-Aksoy E, Yilmaz B, et al. Pregnancy in women with primary biliary cirrhosis. Autoimmun Rev. 2014;13:931-935

214. Floreani A, Infantolino C, Franceschet I, et al. Pregnancy and primary biliary cirrhosis: a case-control study. Clin Rev Allergy Immunol. 2015;48:236-242

215. Chappell LC, Bell JL, Smith A, et al. Ursodeoxycholic acid versus placebo in women with intrahepatic cholestasis of pregnancy (PITCHES): a randomised controlled trial. Lancet. 2019;394:849-860

216. Kong X, Kong Y, Zhang F, et al. Evaluating the effectiveness and safety of ursodeoxycholic acid in treatment of intrahepatic cholestasis of pregnancy: a meta-analysis (a prisma-compliant study). Medicine (Baltimore). 2016;95:e4949

217. de Vries E, Beuers U. Ursodeoxycholic acid in pregnancy. J Hepatol. 2019;71:1237-1245

218. Wellge BE, Sterneck M, Teufel A, et al. Pregnancy in primary sclerosing cholangitis. Gut. 2011;60:1117-1121

219. Rudi J, Schönig T, Stremmel W. Therapy with ursodeoxycholic acid in primary biliary cirrhosis in pregnancy. Z Gastroenterol. 1996;34:188-191

220. Vítek L, Zelenková M, Brůha R. Safe use of ursodeoxycholic acid in a breast-feeding patient with primary biliary cirrhosis. Dig Liver Dis. 2010;42:911-912

221. Al-Harthy N, Kumagi T. Natural history and management of primary biliary cirrhosis. Hepat Med. 2012;4:61-71

222. Christensen E, Crowe J, Doniach D, et al. Clinical pattern and course of disease in primary biliary cirrhosis based on an analysis of 236 patients. Gastroenterology. 1980;78:236-246

223. Locke GR, Therneau TM, Ludwig J, et al. Time course of histological progression in primary biliary cirrhosis. Hepatology. 1996;23:52-56

224. Springer J, Cauch-Dudek K, O'Rourke K, et al. Asymptomatic primary biliary cirrhosis: a study of its natural history and prognosis. Am J Gastroenterol. 1999;94:47-53

225. Prince M, Chetwynd A, Newman W, et al. Survival and symptom progression in a geographically based cohort of patients with primary biliary cirrhosis: follow-up for up to 28 years. Gastroenterology. 2002;123:1044-1051

226. Cheung AC, Lammers WJ, Murillo PCF, et al. Effects of age and sex of response to ursodeoxycholic acid and transplant-free survival in patients with primary biliary cholangitis. Clin Gastroenterol Hepatol. 2019;17:2076-2084.e2

227. Quarneti C, Muratori P, Lalanne C, et al. Fatigue and pruritus at onset identify a more aggressive subset of primary biliary cirrhosis. Liver Int. 2015;35:636-641

228. Jones DE, Al-Rifai A, Frith J, et al. The independent effects of fatigue and UDCA therapy on mortality in primary biliary cirrhosis: results of a 9 year follow-up. J Hepatol. 2010;53:911-917

229. Rigopoulou EI, Davies ET, Pares A, et al. Prevalence and clinical significance of isotype specific antinuclear antibodies in primary biliary cirrhosis. Gut. 2005;54:528-532

230. Wesierska-Gadek J, Penner E, Battezzati PM, et al. Correlation of initial autoantibody profile and clinical outcome in primary biliary cirrhosis. Hepatology. 2006;43:1135-1144 
231. Huang C, Han W, Wang C, et al. Early prognostic utility of Gp210 antibody-positive rate in primary biliary cholangitis: a meta-analysis. Dis Markers. 2019;2019:9121207

232. Gatselis NK, Zachou K, Norman GL, et al. Clinical significance of the fluctuation of primary biliary cirrhosis-related autoantibodies during the course of the disease. Autoimmunity. 2013;46:471-479

233. Roll J, Boyer JL, Barry D, et al. The prognostic importance of clinical and histologic features in asymptomatic and symptomatic primary biliary cirrhosis. N Engl J Med. 1983;308:1-7
234. Vleggaar FP, van Buuren HR, Zondervan PE, et al. Jaundice in non-cirrhotic primary biliary cirrhosis: the premature ductopenic variant. Gut. 2001;49:276-281

235. Murillo PCF, Hirschfield GM, Corpechot C, et al. Fibrosis stage is an independent predictor of outcome in primary biliary cholangitis despite biochemical treatment response. Aliment Pharmacol Ther. 2019;50:1127-1136

Publisher's Note Springer Nature remains neutral with regard to jurisdictional claims in published maps and institutional affiliations.

\title{
Author and Affilation
}

\author{
Hong You ${ }^{1}$. Xiong $\mathrm{Ma}^{2}$. Cumali Efe ${ }^{3}$. Guiqiang Wang ${ }^{4} \cdot$ Sook-Hyang Jeong ${ }^{5} \cdot$ Kazumichi Abe $^{6} \cdot$ Weijia Duan $^{1}$. \\ Sha Chen ${ }^{1}$. Yuanyuan Kong ${ }^{7}$. Dong Zhang ${ }^{8} \cdot$ Lai Wei $^{9} \cdot$ Fu-Sheng Wang ${ }^{10} \cdot$ Han-Chieh Lin ${ }^{11}$. Jin Mo Yang ${ }^{12}$. \\ Tawesak Tanwandee ${ }^{13} \cdot$ Rino A. Gani $^{14}$. Diana A. Payawal ${ }^{15} \cdot$ Barjesh C. Sharma $^{16}$. Jinlin Hou ${ }^{17}$. Osamu Yokosuka ${ }^{18}$. \\ A. Kadir Dokmeci ${ }^{19}$. Darrell Crawford ${ }^{20}$. Jia-Horng Kao ${ }^{21} \cdot$ Teerha Piratvisuth $^{22}$ - Dong Jin Suh ${ }^{23}$. \\ Laurentius A. Lesmana ${ }^{24}$ • Jose Sollano ${ }^{25} \cdot{\text { George } \text { Lau }^{26} \cdot \text { Shiv K. Sarin }}^{27}$ • Masao Omata ${ }^{28,30} \cdot$ Atsushi Tanaka $^{29}$. \\ Jidong Jia ${ }^{1}$ (D)
}

Masao Omata

momata-tky@umin.ac.jp

$\triangle$ Atsushi Tanaka

tanaka@med.teikyo-u.ac.jp

Jidong Jia

jia_jd@ccmu.edu.cn

Hong You

youhongliver@ccmu.edu.cn

Xiong Ma

maxiongmd@hotmail.com

Cumali Efe

drcumi21@hotmail.com

Guiqiang Wang

john131212@sina.com

Sook-Hyang Jeong

jsh@snubh.org

Kazumichi Abe

kazumichi.abe@gmail.com

Weijia Duan

drduan2018@126.com

Sha Chen

chensha@ccmu.edu.cn

Yuanyuan Kong

kongyy@ccmu.edu.cn

Dong Zhang

zhangd@ccmu.edu.cn

Lai Wei

weelai@163.com

Fu-Sheng Wang

fswang302@163.com

Han-Chieh Lin

hclin@vghtpe.gov.tw

Jin Mo Yang

jmyangdr@catholic.ac.kr
Tawesak Tanwandee

tawesak@gmail.com

Rino A. Gani

personaly@yahoo.com

Diana A. Payawal

dianapayawal@yahoo.com

Barjesh C. Sharma

drbcsharma@hotmail.com

Jinlin Hou

jlhou@smu.edu.cn

Osamu Yokosuka

yokosukao@faculty.chiba-u.jp

A. Kadir Dokmeci

akdokmeci@hotmail.com

Darrell Crawford

d.crawford@uq.edu.au

Jia-Horng Kao

kaojh@ntu.edu.tw

Teerha Piratvisuth

teerha.p@psu.ac.th

Dong Jin Suh

djsuh46@naver.com

Laurentius A. Lesmana

llesmana.id@gmail.com

Jose Sollano

joeys_812@yahoo.com

George Lau

gkklau@netvigator.com

Shiv K. Sarin

shivsarin@gmail.com

Liver Research Center, Beijing Friendship Hospital, Capital Medical University, 95 Yong-an Road, Beijing, Mainland, China 
2 Department of Gastroenterology and Hepatology, Renji Hospital, Shanghai Jiao Tong University, Shanghai, Mainland, China

3 Department of Gastroenterology, Gazi Yaşargil Education and Research Hospital, Diyarbakir, Turkey

4 Department of Infectious Diseases and Center for Liver Diseases, Peking University First Hospital, Beijing, Mainland, China

5 Department of Internal Medicine, Seoul National University College of Medicine, Seoul National University Bundang Hospital, Seoul, South Korea

6 Department of Gastroenterology, Fukushima Medical University School of Medicine, Fukushima, Japan

7 Clinical Epidemiology and EBM Unit, Beijing Friendship Hospital, Capital Medical University, Beijing, Mainland, China

8 Experimental and Translational Research Center, Beijing Clinical Research Institute, Beijing, Mainland, China

9 Hepatobiliary Pancreatic Center, Tsinghua Changgung Hospital, Tsinghua University, Beijing, Mainland, China

10 Treatment and Research Center for Infectious Diseases, The Fifth Medical Center of PLA General Hospial, Beijing, Mainland, China

11 Division of Gastroenterology and Hepatology, Department of Medicine, Taipei Veterans General Hospital, Taipei, Taiwan

12 Division of Hepatology, Department of Internal Medicine, College of Medicine, St. Vincent's Hospital, The Catholic University of Korea, Suwon, South Korea

13 Division of Gastroenterology, Department of Medicine, Faculty of Medicine, Siriraj Hospital, Mahidol University, Bangkok, Thailand

14 Department of Internal Medicine, Cipto Mangunkusumo Hospital, University of Indonesia, Jakarta, Indonesia
15 Department of Medicine, Fatima University Medical Center, Manila, Philippines

16 Department of Gastroenterology, GB Pant Hospital, New Delhi, India

17 Department of Infectious Disease and Hepatology Unit, Nanfang Hospital, Southern Medical University, Guangzhou, Mainland, China

18 Department of Gastroenterology, Graduate School of Medicine, Chiba University, Chiba, Japan

19 Department of Medicine, Ankara University School of Medicine, Ankara, Turkey

20 School of Medicine, University of Queensland, Brisbane, Australia

21 Department of Internal Medicine, National Taiwan University Hospital, Taipei, Taiwan

22 NKC Institute of Gastroenterology and Hepatology, Faculty of Medicine, Prince of Songkla University, Hatyai, Thailand

23 Department of Gastroenterology, University of Ulsan College of Medicine, Seoul, South Korea

24 Digestive Disease and GI Oncology Centre, Medistra Hospital, Jakarta, Indonesia

25 Department of Medicine, University of Santo Tomas, Manila, Philippines

26 Humanity and Health Clinical Trial Center, Humanity and Health Medical Group, Hong Kong SAR, China

27 Department of Hepatology, Institute of Liver and Biliary Sciences, Vasant Kunj, New Delhi, India

28 Department of Gastroenterology, Yamanashi Central Hospital, Yamanashi, Japan

29 Department of Medicine, Teikyo University School of Medicine, Tokyo, Japan

30 University of Tokyo, Tokyo, Japan 